\title{
Interchange of Callosal and Association Projections in the Developing Visual Cortex
}

\author{
G. M. Innocenti, S. Clarke, and R. Kraftsik \\ Institute of Anatomy, University of Lausanne, 1005 Lausanne, Switzerland
}

Neurons projecting transitorily into the corpus callosum from area 17 of the cat were retrogradely labeled by the fluorescent tracer Fast Blue (FB) injected into contralateral areas 17 and 18 on postnatal days $1-5$. During the second postnatal month these neurons were still labeled by the early injection, although they had eliminated their callosal axon. At this time, 15-20\% of these neurons could be retrogradely relabeled by injections of Diamidino Yellow (DY) into ipsilateral areas 17 and 18, but few or none by similar injections in the other areas that receive from area 17 (19, 21a, PMLS, 20a, 20b, DLS). Similarly, area 17 neurons projecting transitorily to contralateral area PMLS during the first postnatal week could be relabeled by $D Y$ injections in ipsilateral areas 17 and 18 but not in PMLS. Already around birth, many transitorily callosal neurons in area 17 send bifurcating axons both to contralateral areas 17 and 18 and ipsilateral area 18. It is probable that during postnatal development some of these neurons selectively eliminate their callosal axon collaterals and maintain the projection to ipsilateral area 18. In fact, some transitorily callosal neurons in area $\mathbf{1 7}$ can be double-labeled by simultaneous perinatal injections of FB in contralateral areas 17 and 18 and of a new long-lasting retrograde tracer, rhodamine-conjugated latex microspheres, in ipsilateral area 18 . The same neurons can then be relabeled by reinjecting ipsilateral area 18 with DY during the second postnatal month. This finding, however, does not exclude the possibility that some transitorily callosal neurons send an axon to ipsilateral area 18 after eliminating their callosal axon.

In conclusion, area 17 neurons that project transitorily through the corpus callosum later participate, probably permanently, in ipsilateral corticocortical projections but selectively to areas 17 18. The mechanism responsible for this selectivity is unknown, but it may be related to the differential radial distribution (i.e., to birth date) of area 17 neurons engaged in the various corticocortical projections. The problems raised by the use of longlasting retrograde fluorescent tracers in neurodevelopmental studies and by the quantification of results of double- and triplelabeling paradigms are also discussed.

Corticofugal projections undergo a dramatic reshaping in development (Innocenti et al., 1977). In the corpus callosum of the cat, for example, at least $70 \%$ of the axons present at birth are eliminated (Koppel and Innocenti, 1983). The elimination

Received June 12, 1985; revised Sept. 11, 1985; accepted Oct. 30, 1985.

Preliminary reports of these data were presented at the Eighth European Neuroscience Congress (Neurosci. Lett. Suppl. 18: S177, 1984) and at the Ninth Furopean Neuroscience Congress (Neurosci. Lett. Suppl. 22: S39, 1985). This work was supported by the Swiss National Science Foundation Grant 3.422-0.83 to GMI. We are grateful to S. Daldoss, C. Vaclavik, and H. Van der Loos for their help at various stages of this research. We are especially grateful to P. Clarke for his substantial help with the Appendix. The rhodamine-latex tracer was kindly provided by Drs. A. Burkhalter and L. Katz.

Correspondence should be addressed to Dr. Innocenti, Institut d'Anatomie, rue du Bugnon 9, CH-1005 Lausanne, Switzerland.

Copyright @ 1986 Society for Neuroscience $0270-6474 / 86 / 051384-26 \$ 02.00 / 0$ establishes the adult topography of interhemispheric connections. In fact, of the neonatal projections, only those between certain areas and certain parts of these areas remain in the adult (Innocenti and Clarke, 1984b). Association (Clarke and Innocenti, 1986; Innocenti and Clarke, 1984a) and corticosubcortical projections (Adams et al., 1983; Distel and Holländer, 1980; Stanfield et al., 1982; Tolbert and Pannetton, 1983; Tolbert et al., 1984; Tsumoto et al., 1983) undergo a similar reorganization.

It was shown that the neurons that give rise to the transitory projections do not die, and it was therefore concluded that they probably change target in development (Innocenti, 1981; Innocenti and Clarke, 1984a; Ivy and Killackey, 1982; O'Leary et al., 1981; Stanfield et al., 1982).

How this occurs is not known. A neuron may initially send axon collaterals to several targets, and then eliminate one or more of them. Alternatively, a neuron could, after eliminating its temporary axon, grow a new one to its final target (Innocenti, 1979, 1981).

The first hypothesis (which we will call the collateral selection hypothesis) is intuitively more plausible. It seems to be supported by a classic observation of Cajal (see Innocenti, 1979), and it has gained some popularity (see, for example, Ivy and Killackey, 1982; O'Leary et al., 1981; Schwartz and GoldmanRakic, 1982). Nevertheless, there is no compelling support for this hypothesis, nor has the alternative one (which we will call the regrowth hypothesis) been ruled out. The strongest support for the collateral selection hypothesis comes from studies of callosal connections in the parietal cortex of the rat (Ivy and Killackey, 1982). In this area, in the adult, callosal neurons are distributed in "columns" separated by acallosal gaps, while at birth they are distributed continuously. The neonatal callosal neurons, including those in the gaps, were labeled by a longlasting retrograde tracer injected in the contralateral hemisphere on day 7 and could be relabeled by a later injection of a different tracer in the ipsilateral motor cortex on day 25 , i.e., after the transitory projections had been eliminated. This suggests that some transitorily callosal neurons eventually form association connections. Furthermore, in newborn rats, some neurons in the parictal cortex project to both contralateral parietal and ipsilateral motor areas. The collateral selection hypothesis implies that these neurons are the same transitorily callosal neurons that project to the motor cortex in the adult. Unfortunately, it may not be so. One difficulty is that in the parietal cortex of the rat the transitorily callosal neurons cannot be identified with certainty from their position. In fact, unlike what was originally believed, some callosal neurons can be found in the space between the callosal "columns" even in the adult (Ivy et al., 1984). Furthermore, only a fraction of the neonatal callosal neurons could also be labeled from the motor cortex either before or after the elimination of the transitory callosal projections. Therefore, the callosal neurons that at birth sent a collateral to the ipsilateral motor cortex might (1) keep or (2) eliminate both axons (or even die), while other transitorily callosal neurons 
grew a new axon to the ipsilatcral motor cortex. The results reported here address these points and give some support to the collateral selection hypothesis.

The development of callosal connections shows other, puzzling, and probably more important features. The exuberant neonatal projections are neither random nor totally diffuse. $\mathrm{Al}$ together, different "rules," or "principles," seem to govern the neonatal and the adult organizations (for discussion, see Innocenti and Clarke, 1984b). The transition from the neonatal to the adult organization can be influenced by factors extrinsic to the animal, for example, by visual experience (Berman and Payne, 1983; Elberger et al., 1983; Innocenti and Frost, 1979, 1980; Innocenti et al., 1985).

Here, we investigate what "principles" or "rules" intrinsic to the animal may normally underly the transition, and, in particular, whether a relationship exists between a neuron's initial and final choice of its target. To this end, we try to identify the final target of area 17 neurons that earlier send transitory projections either to contralateral $17 / 18$ or to contralateral PMLS of Palmer et al. (1978). We find that transitorily callosal neurons are selective in the choice of their "final" target and that this selectivity seems to be related to the radial organization of projection neurons in area 17.

\section{Materials and Methods}

The study is based on 24 kittens that were subdivided into four groups (Table 1, Fig. 1). In the first group ( 9 kittens; Fig. $1 B$ ), areas 17 and 18 in one hemisphere were injected with the fluorescent tracer Fast Blue (FB) (Bentivoglio ct al., 1980) at the beginning of the first postnatal week. During the second postnatal month, one or several visual areas in the contralateral hemisphere were injected with Diamidino Yellow dihydrochloride (DY) (Keizer et al., 1983; Figs. 2, 3).

In the second group ( 7 kittens; Fig. $1 B$ ), area PMLS in one hemisphere received multiple $\mathrm{FB}$ injections at the beginning of the first postnatal week. One kitten of this group (DL 122) also received an injection of rhodamine-conjugated latex microspheres (RL) (Katz et al., 1984) in area 18 homolateral to the injected PMLS. During the second postnatal month, three of these kittens received DY injections in the contralateral area PMLS, three in the contralateral area 18 (and 17), and one in areas 20a, 20b, DLS (Fig. 10).

In the third group ( 5 kittens; Fig. $1 C$ ), visual areas in the two hemispheres were simultaneously injected with either FB, DY, or nuclear ycllow (NY) (Bentivoglio et al., 1980) at the beginning of the first postnatal week. Three combinations of injections were used: 17-18 and contralateral 17-18, 17-18 and contralateral PMLS, PMLS and contralateral PMLS (Fig. 13). One of these kittens (DL 113) also received an early application of dry rhodamine crystals near the $17 / 18$ border simultaneously to the FB injection and on the same side. The results of the rhodamine application will not be described here.

Finally, three kittens (Fig. $1 D$ ) received simultaneous injections of FB in areas 17 and 18 of one hemisphere and of RL in contralateral 18 at the beginning of the first postnatal week. During the second postnatal month these kittens were reinjected with DY in area 18 on the side of the RL injection (Fig. 13).

Kittens were killed 4-9 days after the last injection (Table 1). In all the animals, the extent and location of the injections were determined by criteria similar to those used previously (Innocenti and Clarke, 1984b) and by comparison with the electrophysiological maps of the visual areas (Palmer et al., 1978; Tusa and Palmer, 1980; Tusa et al., 1978, 1979).

The techniques for injection and processing of the brains were as described elsewhere (Innocenti, 1981; Innocenti and Clarke, 1984b). Kittens were premedicated with atropine, anesthetized with Ketalar (30 $\mathrm{mg} / \mathrm{kg}$ ), supplemented by inhalation of a mixture of $\mathrm{O}_{2}$ and either Penthrane or $0.5-2.00 \%$ Fluothane. Aqueous solutions of FB, DY (respec-

Figure 1. Questions, methods, and results. $A$, At time T0 (first postnatal week), area 17 neurons project to contralateral areas 17 and 18 or to PMLS; at time T1 (second postnatal month), these neurons have eliminated their callosal axon. Where do they project? And did they already have a collateral to their final target at $\mathrm{T} 0$ ? $B$, FB was injected
A
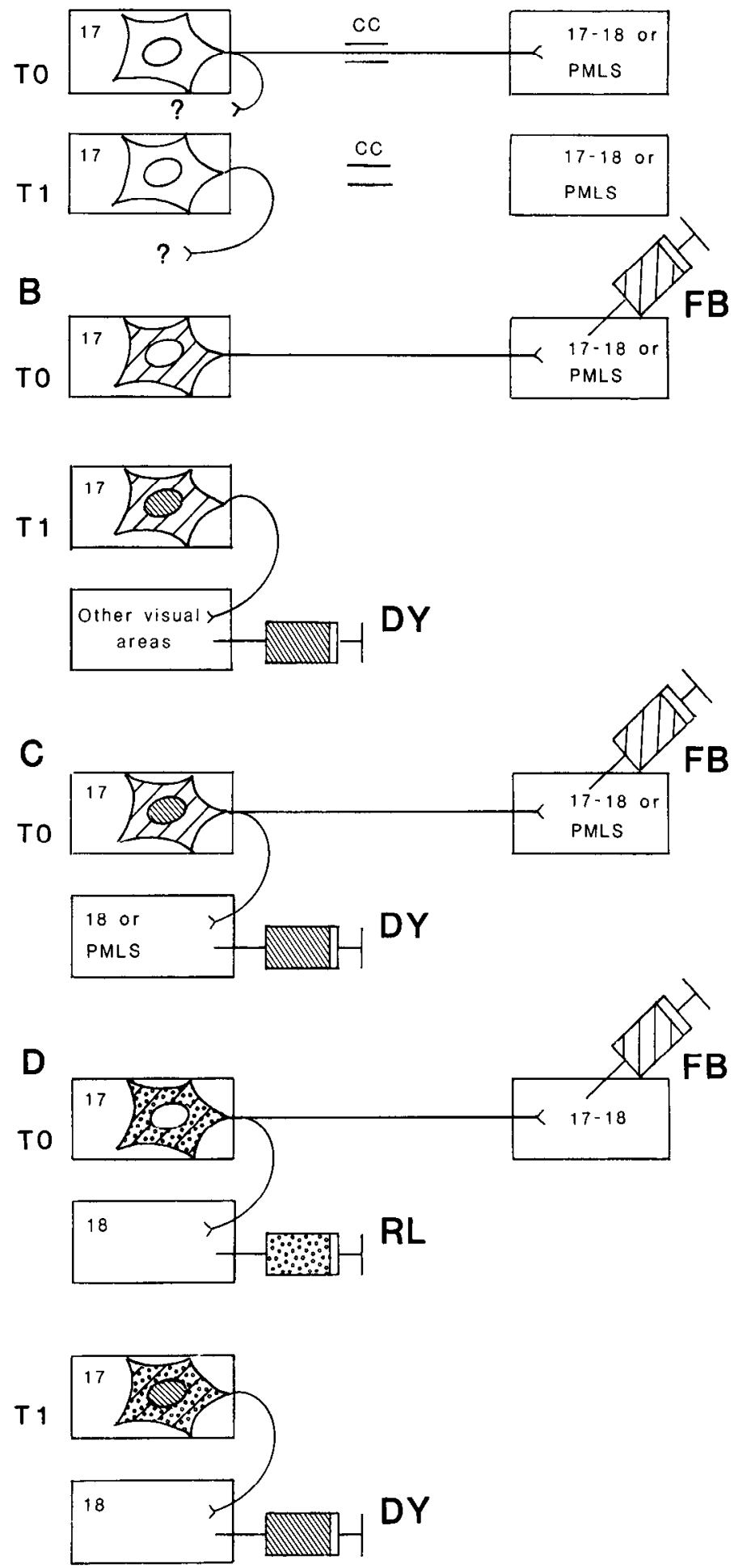

into areas $17-18$ or PMLS at T0; this tracer provides long-lasting labeling of neuronal cytoplasm. At T1, DY was injected in various visual areas contralateral to the FB injection; some neurons that previously projected through the corpus callosum are relabeled. $C$, FB is injected as in $B$; DY is simultaneously injected at T0 in either area 18 or PMLS, double-labeling some transitorily callosal neurons; unlike in $B$ and $D$, the animal is killed after a few days' survival. $D$, At T0, FB is injected as in $B$ and $C$, and RL is injected in area 18. At T1, DY is reinjected in area 18. The results are consistent with the hypothesis that some of the transitorily callosal neurons in area 17 have an axon collateral to ipsilateral area 18 and maintain it after eliminating their transitory callosal axon. 
Table 1. Summary of experiments

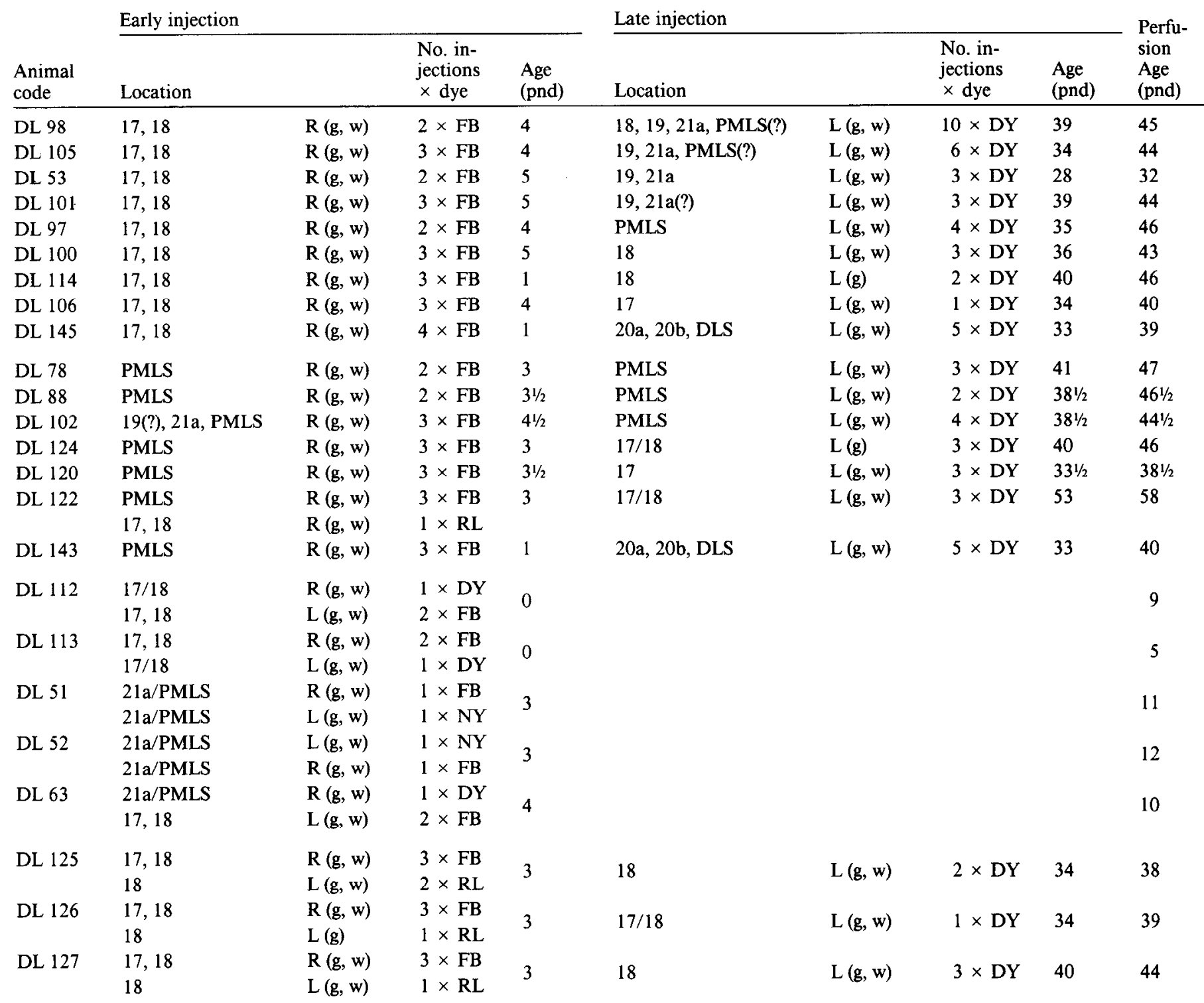

Animals are divided into blocks illustrating the different experiments described in the text. Animals in each block are also in the same order as discussed in the text. Abbreviations: g, gray matter; w, white matter; R, L, right, left hemisphere; $1 \times-4 \times$, one to four injections; /, border between areas (e.g., $17 / 18=$ border between areas 17 and 18); ?, uncertain injection location; pnd, postnatal day. For other abbreviations see text.

tively, 1.5 and $2 \%)$, and RL $(0.02-0.2 \mu \mathrm{m}$ in diameter; obtained from Boys Burge International Diagnostics Technology, Santa Clara, CA) were injected through a stereotactically mounted 5 or $10 \mu 1$ Hamilton microsyringe with a sharpened needle. Brain injections were carried out under aseptic conditions. Kittens were perfused with $30 \%$ buffercd formalin (pH 7.1) followed by $20 \%$ buffered sucrose (same $\mathrm{pH}$ ). The brains were stored in $30 \%$ sucrose solution overnight and cut frozen on a cryostat $(30 \mu \mathrm{m})$.

Sections were examined with a Zeiss fluorescence microscope equipped with the following combinations of excitation/barrier filters: 360-370/
$397,395-425 / 450,402-408 / 435$, and $510-560 / 590 \mathrm{~nm}$. For a first survey 6.3 and $16 \times$ objectives were used. Injection sites were sketched on $10 \times$-enlarged drawings of section outlines. The degree of overlap in area 17 of neurons labeled by the FB and DY (and/or RL) injections was determined, and brains with insufficient overlap were discarded from further study (and from Table 1). Of course, in these brains there were no double-labeled neurons. In the other brains, two to six sections were selected from the rostrocaudal levels containing the highest packing density of DY-labeled neurons (see Appendix). The distribution of labeled neurons was charted with a microscope similar to that used for

Figure 2. $A$, Site of FB injection in areas 17, 18, and underlying white matter in DL 106 (injected on day 4, killed on day 40). Dorsal is up, the medial surface of area 17 to the right. $B, \mathrm{DY}$ injection through area 18 in DL.114 (DY injected on day 40, killed on day 46). Dorsal is up and to the right. Drawings of the same injection site but from adjacent sections are also shown in Figure 3. $C$, Two RL-labeled transitorily callosal neurons in medial area 17 in DL 122 (RL injected in contralateral areas 17 and 18 on day 3, killed on day 58). $D$, Transitorily callosal neuron in medial 

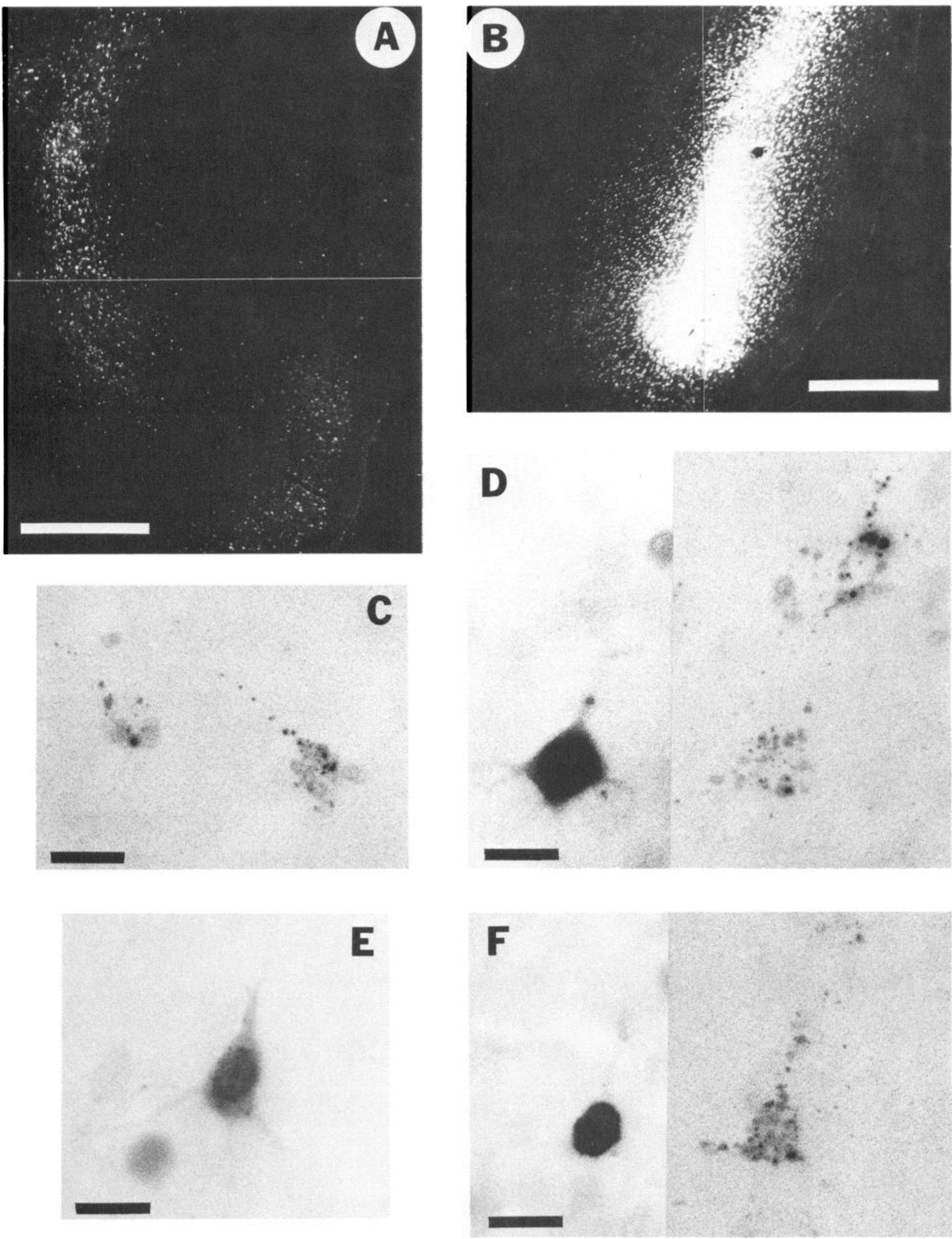

area 17 double-labeled with FB (left) injected in contralateral areas 17 and 18 and RL (bottom right) injected in ipsilateral area 18 (DL 126 , FB and RL injected on day 3, killed on day 39). Another neuron labeled only by RL is also shown (top right). $E$, Transitorily callosal neuron in medial area 17 double-labeled with FB and DY (note the cytoplasmic and nuclear labeling) in DL 126 (DY was injected near the ipsilateral 17/18 border on day 34); a neuron faintly labeled only by DY is also shown. $F$, Neuron in area 17 double-labeled with DY (left) and RL (right) from ipsilateral area 18 (DL 127; RL was injected on day 3, DY on day 40, the animal was killed on day 44 ). $C-F$, Direct prints from color slides; therefore, contrast is reversed with respect to $A$ and $B$. Calibration bars: $500 \mu \mathrm{m}$ in $A$ and $B ; 10 \mu \mathrm{m}$ in $C-F$. 
survey but equipped with a stage whose $x-y$ movements were driven by stepping motors and recorded by a computer. The sections were studied uncoverslipped using a $63 \times$ oil-immersion objective. Since many corticocortically projecting neurons were faintly labeled, especially after the short or very long survivals used here, the high-power objective was essential for an accurate detection of labeled neurons. Labeled elements (Fig. 2) were identified according to the following criteria. FB-labeled neurons can be distinguished from occasionally labeled glia by the size of their cell bodies, usually larger than that of glia; their nucleus is only rarely labeled. FB-labeled glia are occasionally found near intensely labeled neurons; their nucleus is often strongly labeled and sometimes their processes are too. Occasionally, elements that may be dying neurons or.glia are seen: They have a picnotic nucleus and an irregularly shaped soma. RL-labeled neurons contain a variable number of small red grains in their somata and in the initial part of their processes. Faintly RL-labeled neurons are difficult to distinguish from the background containing labeled processes of neurons whose soma is out of the plane of section. Neurons double-labeled with FB and DY have, when illuminated in the UV range, blue cytoplasm and yellow nucleus. Very often though, the cytoplasm adds to the nucleus a bluish overtone, and, in this case, the double-labeled neurons are difficult to distinguish from single-labeled ones, with FB-labeled nucleus. In the very dubious cases, we sometimes found it useful to bleach the FB by keeping it long under illumination. Sections were scanned in $100 \mu \mathrm{m}$ wide parallel tracks perpendicular to the medial bank of the hemisphere. Where association neurons were too densely packed, they were charted in $50 \mu \mathrm{m}$ wide tracks spaced $100 \mu \mathrm{m}$ apart. The charts were printed on an electrostatic plotter.

After toluidine bluc ( $1 \%)$ counterstaining, section outlines and layer boundaries were redrawn, using a computer microscope (Glaser and Van der Loos, 1965) and superposed on the charts of labeled neurons. The number of labeled neurons per section was counted between the crest of the lateral or postlateral gyrus and that of the suprasplenial gyrus.

The criteria for definition of layers were similar to those of Otsuka and Hassler (1962). In particular, the bottom layer III corresponds to that of a group of medium-size pyramids and the upper part of layer IVab to a region of large granules often less densely packed than cells above or below. Layer IVc is a narrow region of densely packed small granules, which others sometimes include in layer V (Lund et al., 1979; O'Leary, 1941). Layer V is the cell-poor zone containing large pyramids. It was impossible to define with certainty the border between layers II and III, which was thereforc set halfway between the bottoms of layers I and III. In young kittens the precise definition of the layers was more difficult: Layer $V$ corresponds to a zone of large pyramids that can be easily identified. However, the cell density in this layer is higher than in the adult, where it stands out more clearly. The border between layers III and IV can be determined by criteria similar to those used in the older kittens, but with difficulty; usually it falls about halfway between the bottom of layer I and the top of IVc. Unfortunately, the upper border of layer IVc in the young kitten is not always easy to distinguish, because the size of stellate cells is very similar to that in IVab. In most cases one can only rely on a slightly higher cell density in IVc.

\section{Results}

\section{Long-lasting labeling of callosal neurons in development}

As already described elsewhere (Innocenti, 1981), in kittens injected with FB in areas 17 and 18 during the first postnatal week and killed during the second postnatal month, labeled neurons in the contralateral hemisphere have a widespread tangential distribution, similar to that found at the time of injection (cf. Figs. 4-9 and 14, 15). In contrast, the origin of callosal projections has already become restricted to near the $17 / 18$ border during the second and third week, although the restriction is completed much later (Innocenti and Caminiti, 1980).

These results were further confirmed in this study by using a new tracer. In DL 122 a similar widespread distribution of labeled neurons was found near the end of the second postnatal month following a neonatal injection of $\mathrm{RL}$ that, as FB, produces long-lasting labeling of neuronal cytoplasm.

The projection from areas $17-18$ to contralateral PMLS also has a widespread origin in newborn kittens, although in the adult it originates only from near the $17 / 18$ border (Innocenti and Clarke, 1983, 1984b). In the present study, neonatal FB injections in area PMLS, followed by long survival, resulted in a widespread distribution of labeled neurons similar to that existing at the time of injection (Figs. 11,12). Thus, the callosal projection to PMLS, as that to 17-18, becomes reorganized by axon elimination.

With long survival, the intensity of retrograde labeling of individual neurons tends to increase, most noticeably when FB is used. This dye seems to be slowly cleared from the injection site and therefore neurons probably continue to take it up and transport it for some time after the injection. However, not all neurons are equally intensely labeled. In particular, callosal neurons near the $17 / 18$ border, probably because they maintain their callosal axon, tend to become more intensely labeled than the transitorily callosal neurons in the rest of area 17 after perinatal injections and long survival.

There is no evidence that the long survival may have led to diffusion of the tracers from the callosal neurons to other elements, with the exception of the rare labeling of glial cells near neurons very intensely labeled with FB. In particular, labeled neurons were not grouped in small clusters, as one would have expected had the tracers diffused among neighboring neurons. Furthermore, increasing the survival times after neonatal tracer injections also did not change the radial distribution of callosal neurons labeled in area 17 (see below), nor did it label the ipsilateral thalamic nuclei, as one might have expected had the tracer diffused into the extracellular space.

\section{Searching for the final target of area 17 neurons that project transitorily to contralateral \\ areas 17 and 18}

This section describes the results of neonatal FB injections in areas 17 and 18 of the right hemisphere and DY injections in various visual areas of the left hemisphere at the end of the first postnatal month or during the second postnatal month (Table 1, Fig. $1 B$ ). The left arca 17 was studicd. In all these kittens (but, for DL 145, see below), the FB- and DY-labeled neurons were distributed over overlapping domains. Transitorily callosal neurons were identified by their location medially to the crest of the lateral and postlateral gyri. This part of area 17 contains only a few callosal neurons in normal adults and only in its dorsal part, i.e., above the suprasplenial sulcus (Innocenti, 1980; Innocenti et al., 1985; Segraves and Innocenti, 1985). The bulk of transitorily callosal neurons was in layers III and IVab, although a few could be found in other layers (see below).

DL 98 (Figs. 3, 4) received 10 DY injections involving the gray and the white matter of areas 18, 19,21a, and probably the medial part of PMLS. In area 17 ipsilateral to the DY injection, the numerous association neurons were somewhat unhomogeneous in their tangential distribution, although clearcut "columns" could not be observed. Association neurons were similar to callosal neurons in their radial distribution; however, they extended more superficially than the latter and were also relatively more numerous in layer VI. Throughout area 17, a high proportion (14.4\%; Table 2 ) of the transitorily callosal neurons were relabeled by the ipsilateral injections. This estimate does not include the numerous relabeled neurons at the periphery of the DY injection site, because it is unclear how these neurons may have been labeled by this tracer. An approximately equal proportion of transitorily callosal neurons was relabeled in layers III and IVab, fewer in layer II.

The kitten DL 105 (Figs. 3, 5) received six DY injections over a region similar to that covered by the same dye in DL 98 but excluding area 18. DL 53 and 101 were injected with DY in areas 19 and 21a, DL 97 in PMLS (Figs. 3, 6, 7). In all these 

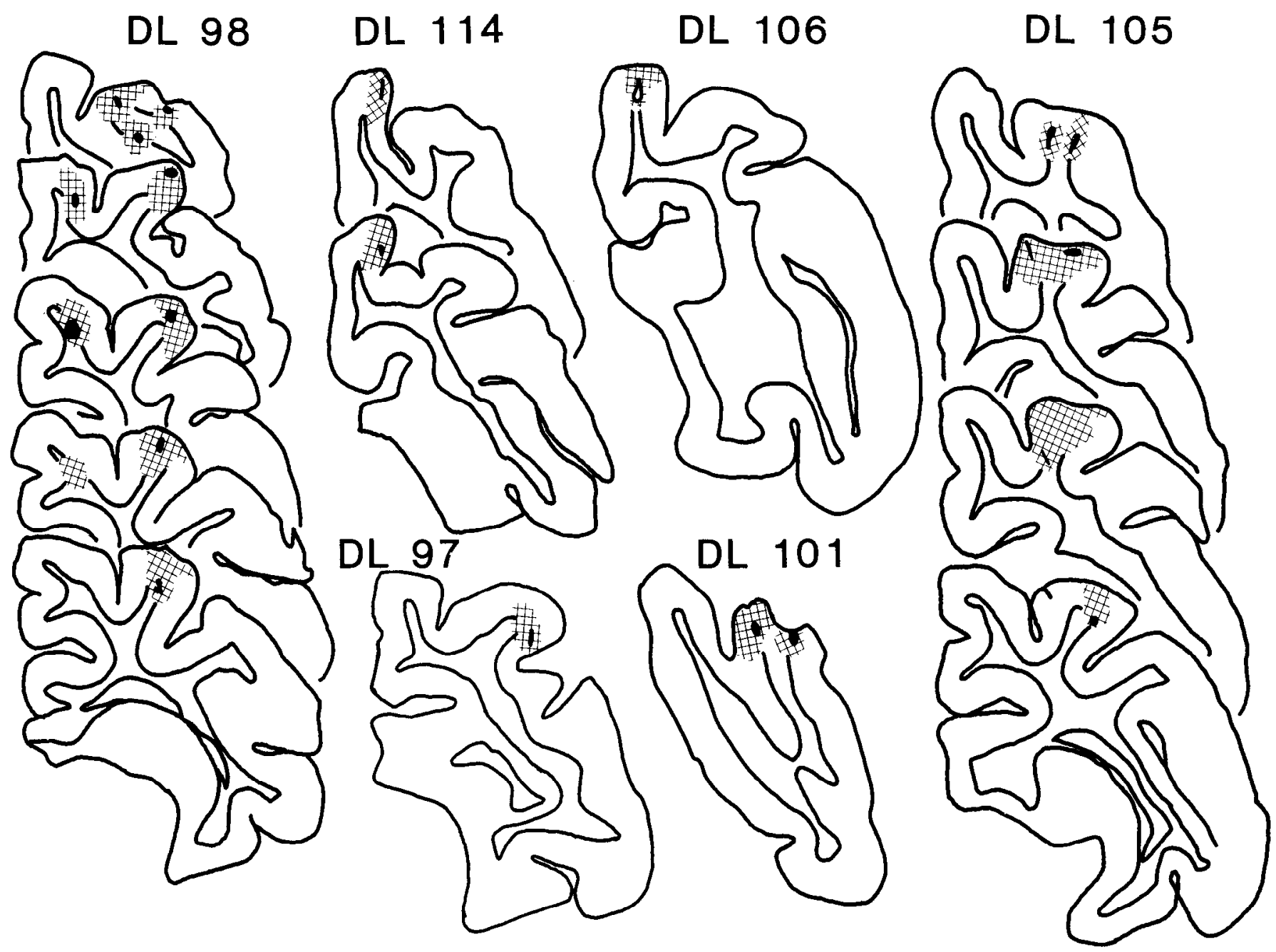

Figure 3. Late DY injection sites in a selected group of kittens with neonatal FB injection in contralateral areas 17 and 18 . The centers of injections and/or needle tracks are black. The shading corresponds to regions where apparently all cells are labeled by the tracer. Left hemispheres are shown, as seen from the front.

animals, no or few transitorily callosal neurons were relabeled (Table 2), although the distributions of early- and late-labeled neurons overlapped extensively. Unlike in DL 98, the association neurons were on average more superficial than the transitorily callosal neurons, reaching their peak density in layers II or III. In DL 53, 101, and 97, the association neurons were discontinuously distributed in "columns" separated by spaces containing either no labeled neurons or just a few.

The nearly complete failure to relabel transitorily callosal neurons in the kittens DL 53, 97, 101, and 105 indicated that the relabeling obtained in DL 98 was probably due to the involvement of area 18 in the late injections. Indeed, many transitorily callosal neurons could be relabeled in DL 100 and in DL 114, whose area 18 (and in DL 114 part of area 17) was injected.

In particular, DL 114 (Figs. 2, 3, 8) received two DY injections in area 18 (extending for a few hundred microns into 17). Both injections were in the gray matter. Association neurons were distributed in "columns" separated by spaces with few or no labeled neurons and were most numerous in granular and supragranular layers, where their relative number decreased progressively from layer IVab to layer II. The distribution was very similar to that observed in DL 98, but, unlike in the latter, there were few neurons in layer VI, and only a few more in V. A considerable fraction of transitorily callosal neurons $(11.6 \%$;
Table 2) was relabeled by the DY injections. These neurons were scattered through area 17 , but became more numerous near the injection site. Similar proportions of neurons were relabeled in layers III, IVab, and VI.

In another animal of this group (DL 106; Figs. 2, 3, 9), the DY injection was restricted to area 17 , mainly to the gray matter. Only a small part of area 17 immediately adjacent to the injection site was labeled, and this resulted in a modest overlap with the FB-labeled territory. The radial distribution of association neurons was different from that observed after area 18 injections. Labeled neurons were most common in layer II and decreased progressively in III and IVab. Labeled neurons were rare in VI and slightly more common in V. A substantial number of callosal neurons were relabeled (5.1\%; Table 2). This figure excludes neurons at the periphery of the DY injection site because it is unclear how they may have been labeled.

The experiment $D L 145$ (Table 1) was meant to test whether transitorily callosal neurons form projections to the ventral visual areas, of which at least area 20a seems to receive a projection from area 17 (Symonds and Rosenquist, 1984a). In this animal, DY was distributed in five injections extending over 20a, 20b, and DLS. As in the case illustrated by Symonds and Rosenquist (1984a; see their Fig. 16) and in spite of our more massive injections, retrograde labeling in area 17 was restricted to near the fundus of the splenial sulcus. At least part of the 


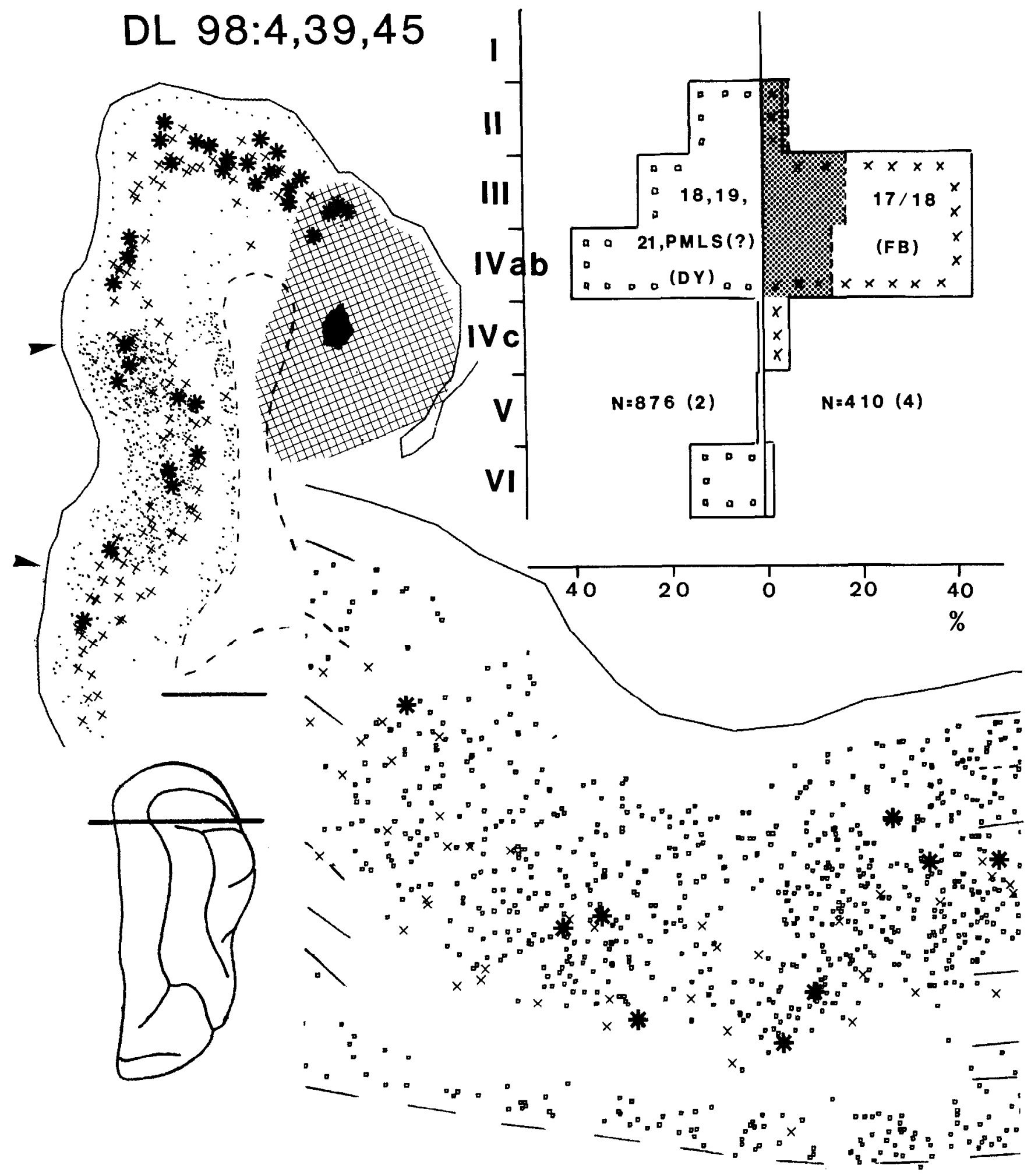

Figure 4. Callosal neurons (crosses) in area 17, labeled by neonatal FB injections in contralateral areas 17 and 18 and association neurons (squares or dots) labeled by late DY injections in various ipsilateral visual areas (see Fig. 3) in DL 98. Double-labeled neurons are shown by asterisks. The heading indicates age of the kitten (in postnatal days) at the time of FB injection, DY injection, and perfusion. Neurons were charted in a coronal section through areas 17 and 18 at the level shown in the brain (inset redrawn from a dorsal view photograph). Calibration bar, $1 \mathrm{~mm}$. DY-labeled neurons were charted only in part of the section; elsewhere, the upper and lower borders of the DY-labeled zones are marked by dots; an interrupted line marks the lower border of layer VI. The shading corresponds to the injection in area 18. The part of the section between the arrows is also reproduced at higher magnification: short segments mark the bottoms of layers I, III, IVab, IVc, V, and VI as determined after counterstaining the section; an interrupted segment shows the arbitrary location of the border between layers II and III. The histogram outlined with crosses shows the distribution of FB-labeled callosal neurons in different layers as a percentage of the total FB-labeled population; site of injection, total number of labeled neurons, and number of sections (between parentheses) are also indicated. The histogram outlincd with squares similarly shows the radial distribution of the DY-labeled association neurons. Hatched columns correspond to neurons labeled by both FB and DY as a percentage of the total FB-labeled neurons in each layer. 
DL $105: 4,34,44$

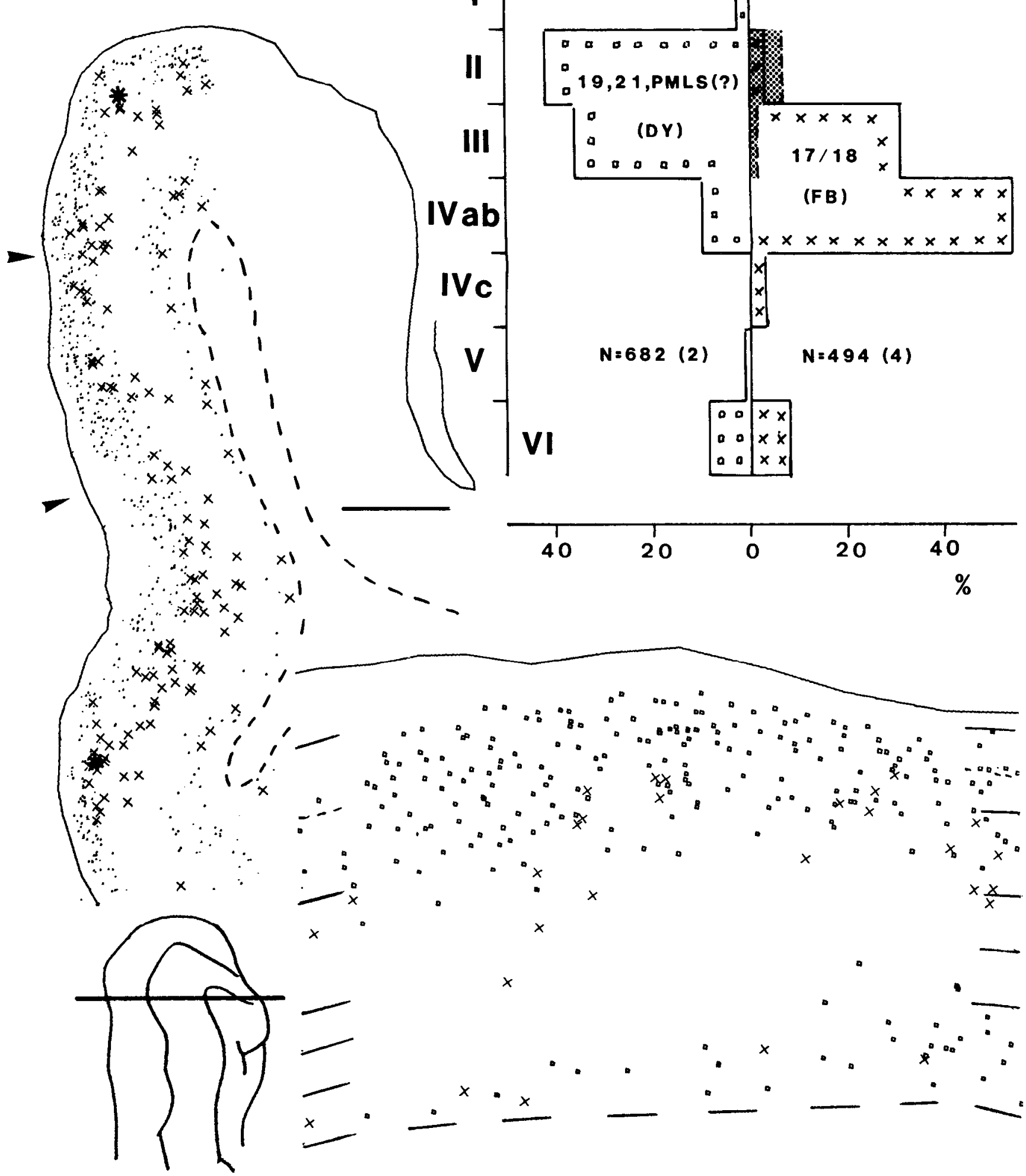

Figure 5. Callosal neurons (crosses) in area 17, labeled by neonatal FB injections in contralateral areas 17 and 18 and association neurons (squares or dots) labeled by late DY injections in various ipsilateral visual areas (see Fig. 3) in DL 105. Double-labeled neurons are shown by asterisks. All conventions as in Figure 4, but DY-labeled cells were charted throughout arca 17.

labeling may have been in a region that was previously found to project into the corpus callosum in the adult (Innocenti, 1980) and was tentatively identified as the "splenial visual area" of Kalia and Whitteridge (1973). FB-labeled neurons were intermingled with the DY-labeled ones, but no double-labeled neurons were found.
In summary (Table 2), a nonnegligible fraction of the transitorily callosal neurons labeled by the early FB injection in contralateral 17 and 18 could be relabeled from ipsilateral area 18. Some neurons could be relabeled from ipsilateral area 17 (see Discussion), very few or none from the other visual areas to which area 17 is known to proiect. 
DL 101:5,39,44

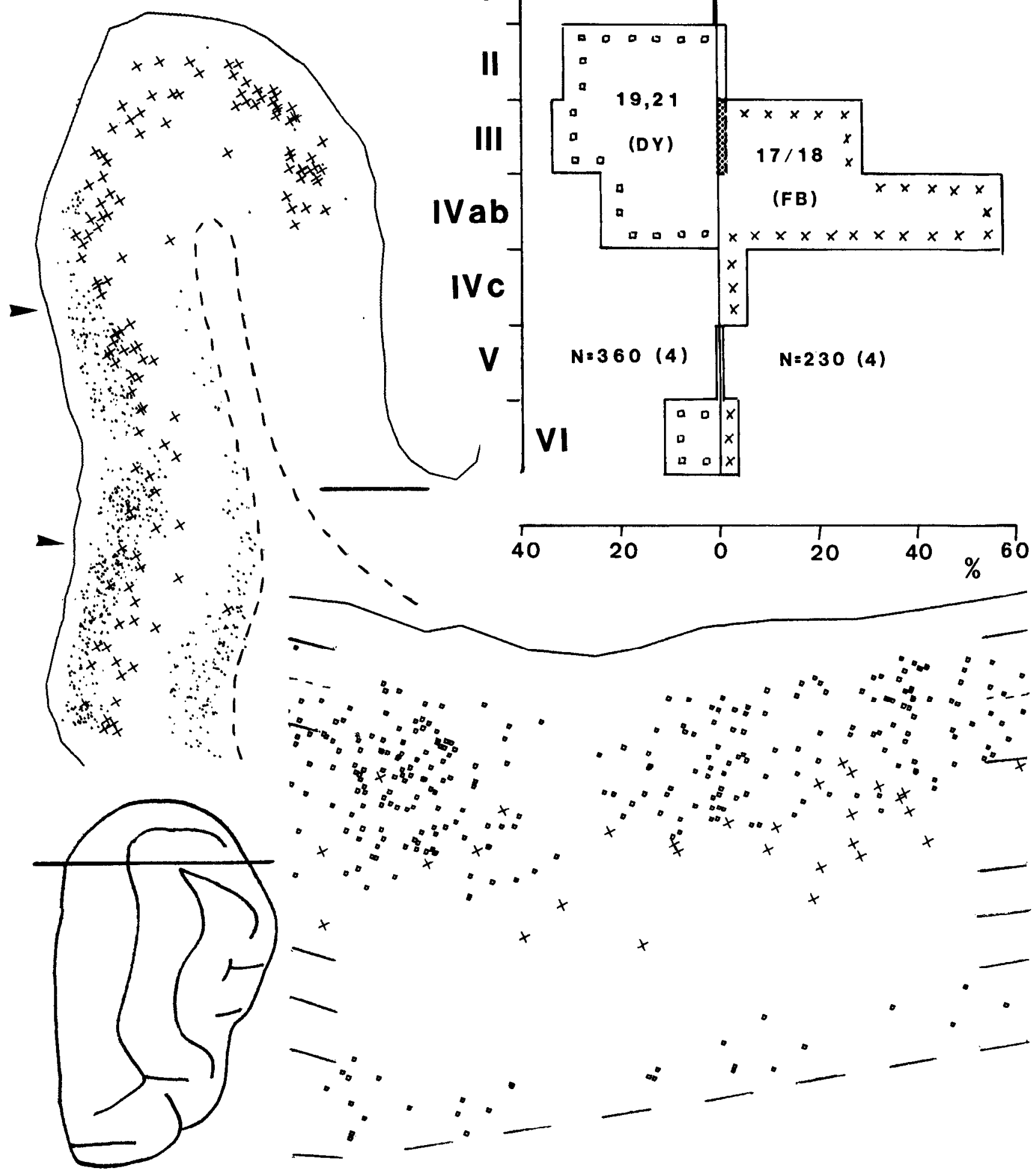

Figure 6. Callosal neurons (crosses) in area 17, labeled by neonatal FB injections in contralateral areas 17 and 18 and association neurons (squares or dots) labeled by late DY injections in ipsilateral areas 19 and 21a (see Fig. 3) in DL 101. All conventions as in Figures 4 and 5.

Searching for the final target of area 17 neurons that project transitorily to contralateral area PMLS

A possible explanation for the selectivity that the transitorily callosal neurons to areas 17 and 18 display in the choice of their late, probably permanent, target could be that they are guided by specific affinities to an area. That is, they may be programmed to project to areas 1.7 and/or 18 independently of brain side. The fact that in newborn kittens neurons in area 17 project transitorily to either contralateral areas $17-18$ or PMLS but not to both (Innocenti and Clarke, 1983, 1984b) provides a way to test this hypothesis. Indeed, the hypothesis predicts that neurons 


\section{DL $97: 4,35,46$}
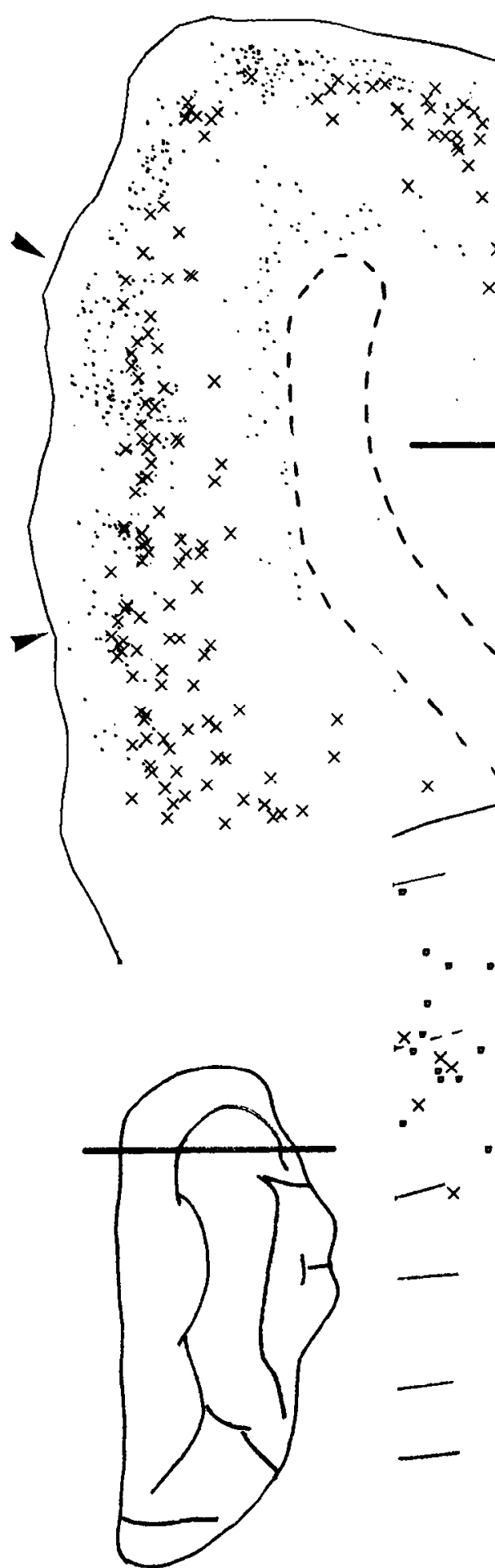

$$
x
$$
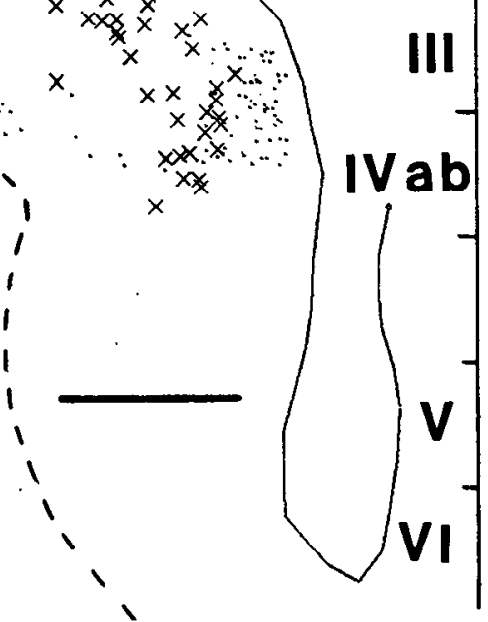

IV c

$N=758$ (4)

$N=165(4)$
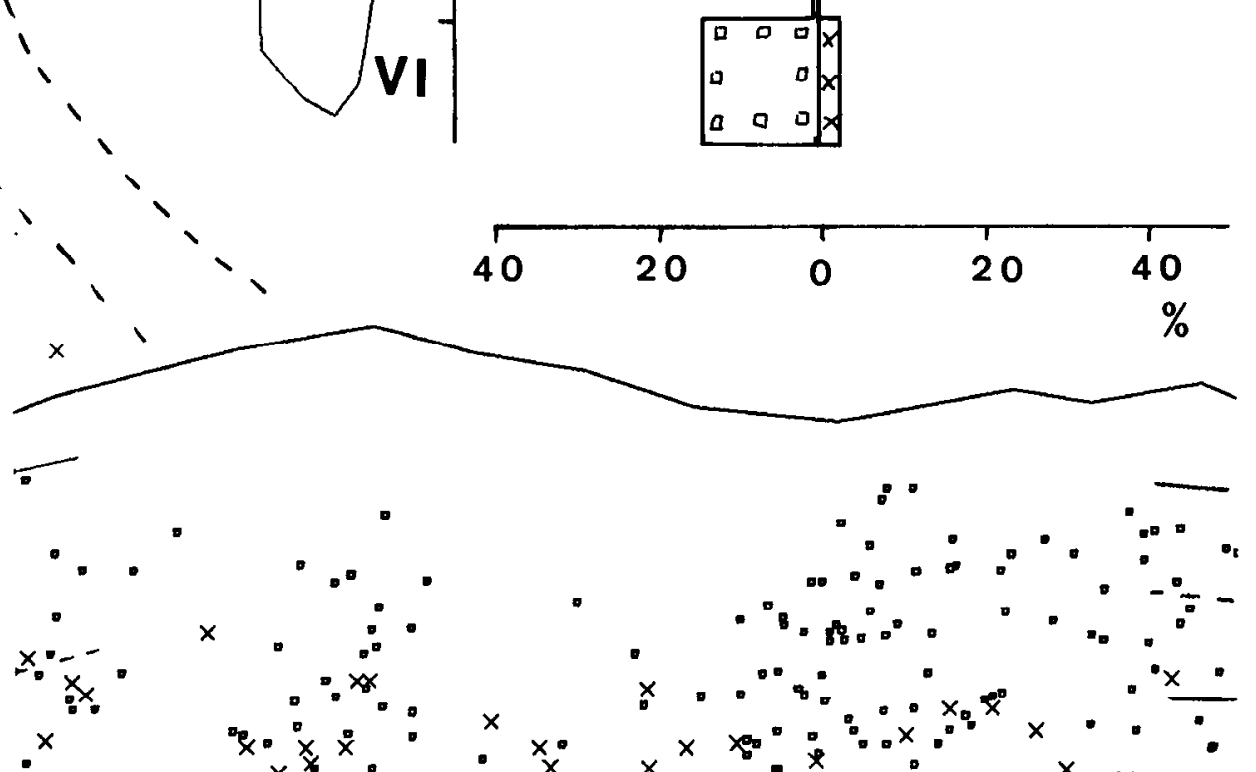

$x$
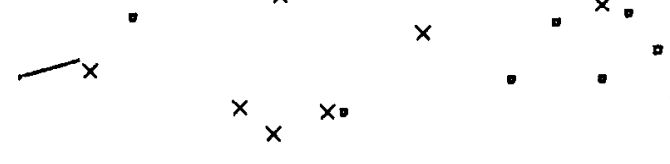

.

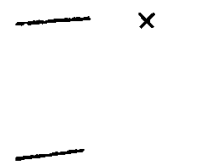

$\times x$

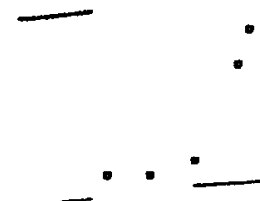

Figure 7. Callosal neurons (crosses) in arca 17, labeled by neonatal FB injections in contralateral areas 17 and 18 and association neurons (squares or dots) labeled by late DY injections in ipsilateral area PMLS (see Fig. 3) in DL 97 . All conventions as in Figures 4 and 5 . Note that no doublelabeled neurons were found in this experiment.

that project transitorily to contralateral PMLS ought to establish permanent connections selectively with ipsilateral PMLS. This section describes the results obtained in kittens that received neonatal FB injections in area PMLS of the right hemisphere and DY injections in either area PMLS or in 17 and/or 18 of the left hemisphere during the second postnatal month. In one case, areas $20 \mathrm{a}, 20 \mathrm{~b}$, and DLS were injected with DY. Left area 17 was studied. 


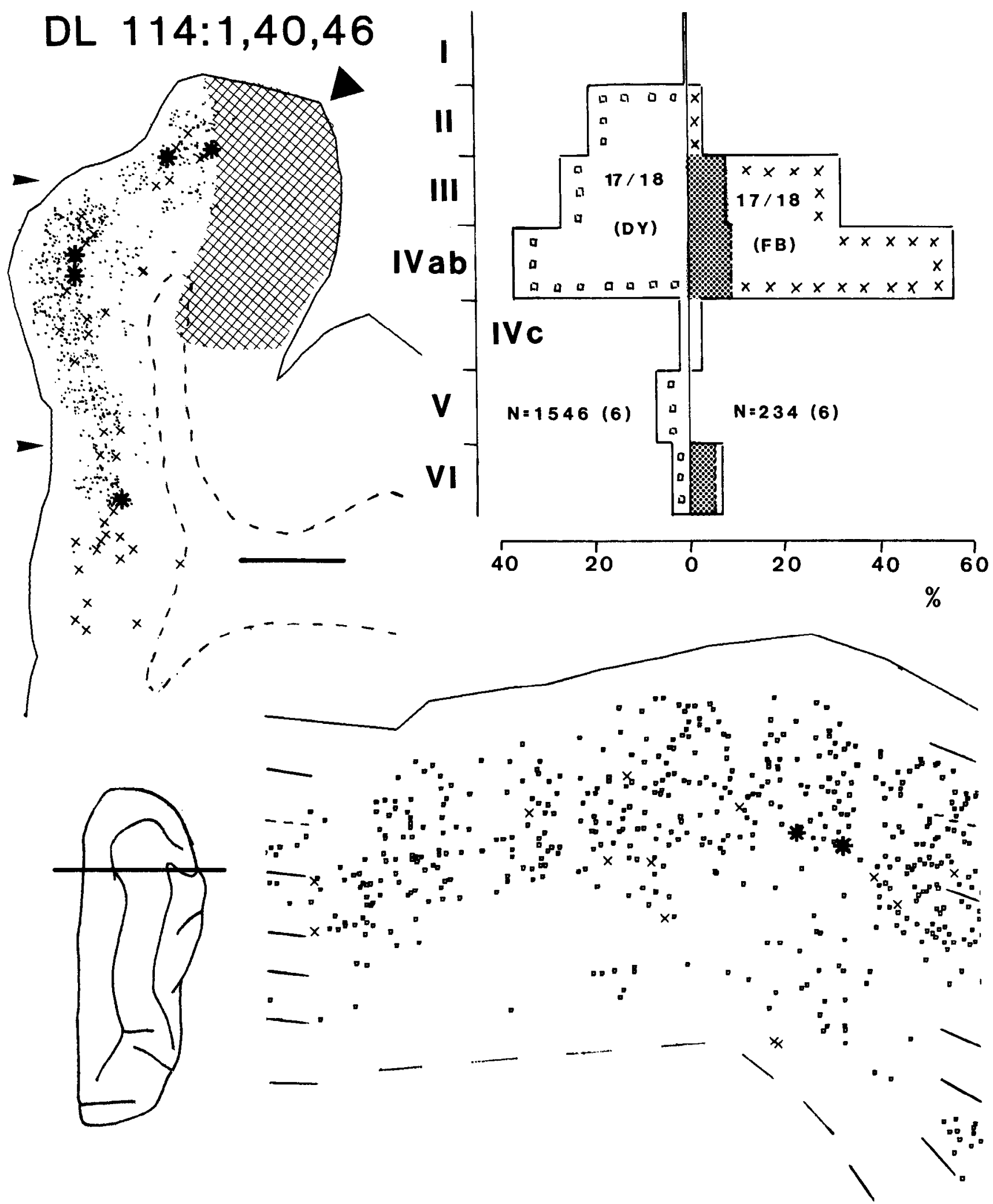

Figure 8. Callosal neurons (crosses) in area 17, labeled by neonatal FB injections in contralateral areas 17 and 18 and association neurons (squares or dots) labeled by late DY injections in ipsilateral area 18 (corresponding to the rostral injection in Fig. 3) in DL 114 . Double-labeled neurons are shown by asterisks. Filled triangle marks $17 / 18$ border. All conventions as in Figures 4 and 5.

Two of the kittens with late DY injections in PMLS (DL 78 and 88; Figs. 10, 11) had no double-labeled neurons in area 17 where, however, neurons labeled by either FB or DY overlapped extensively. The radial distribution of association neurons was similar to that found in DL 97 (Fig. 7); on average they were more superficial than callosal neurons. Two double-labeled neurons were found in two charted sections in the third kitten (DL 102; Table 2), where, however, the early FB injection was not 


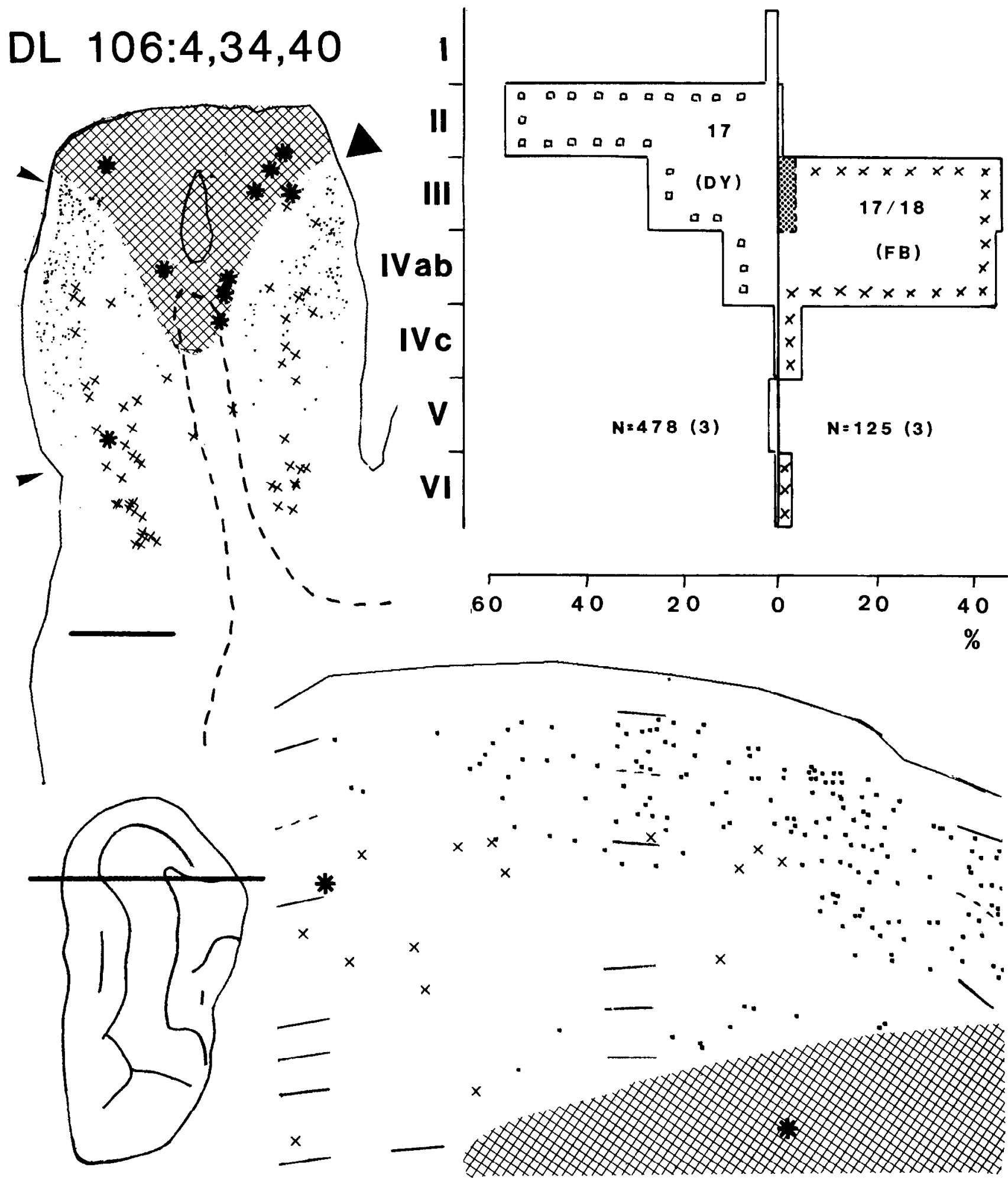

Figure 9. Callosal neurons (crosses) in area 17, labeled by neonatal FB injections in contralateral areas 17 and 18 and association neurons (squares or dots) labeled by a late DY injection in ipsilateral area 17 in DL 106. Double-labeled neurons are shown by asterisks. Filled triangle marks $17 / 18$ border. All conventions as in Figures 4 and 5.

restricted to PMLS, but also involved the white matter under area $21 \mathrm{a}$ and probably under 19.

In contrast to what was found after late PMLS injections, several transitorily callosal neurons in area 17 could be relabeled when area 18 and/or 17 were the targets of the late injections. In experiment DL 124 (Figs. 10, 12), for example, about
$5 \%$ of the transitorily callosal neurons were relabeled by the rostral-most DY injection, which was in the gray matter of area 18 (Table 2). This injection was very similar to that in DL 114, although somewhat smaller; it yielded similar tangential and radial distributions of labeled neurons, although their packing density was slightly lower. Fewer callosal neurons (2.17\%; Table 
Table 2. Projection of juvenile callosal neurons to different ipsilateral areas

\begin{tabular}{|c|c|c|c|c|c|}
\hline $\begin{array}{l}\text { Animal } \\
\text { code }\end{array}$ & $\begin{array}{l}\text { Site of early } \\
\text { injection }\end{array}$ & Site of late injection & $\frac{\mathrm{CC}+\text { Assoc }}{\mathrm{CC}}$ & $\begin{array}{l}\frac{\mathrm{CC}+\mathrm{Assoc}}{\mathrm{Assoc}} \\
\times 100^{a}\end{array}$ & $\begin{array}{l}\mathrm{CC}+ \\
\text { Assoc } \\
(n)\end{array}$ \\
\hline DL 98 & 17,18 & $18,19,21 \mathrm{a}$, PMLS(?) & 14.4 & - & 59 \\
\hline DL 105 & 17,18 & 19, 21a, PMLS(?) & 1.25 & 0.25 & 2 \\
\hline DL 101 & 17,18 & $19,21 a$ & 0.61 & - & 1 \\
\hline DL 97 & 17,18 & PMLS & 0 & 0 & 0 \\
\hline DL 100 & 17,18 & 18 & 6.47 & - & 18 \\
\hline DL 114 & 17,18 & $18^{b}$ & 11.6 & 0.68 & 20 \\
\hline DL 106 & 17,18 & 17 & 5.13 & 0.42 & 2 \\
\hline DL 145 & 17,18 & $20 \mathrm{a}, 20 \mathrm{~b}, \mathrm{DLS}$ & 0 & 0 & 0 \\
\hline DL 78 & PMLS & PMLS & 0 & 0 & 0 \\
\hline DL 88 & PMLS & PMLS & 0 & 0 & 0 \\
\hline DL 102 & 19(?), 21a, PMLS & PMLS & 2.9 & 0.86 & 2 \\
\hline DL 120 & PMLS & 17 & 2.17 & 0.17 & 2 \\
\hline DL 124 & PMLS & $17 / 18$ & 4.8 & 0.36 & 5 \\
\hline DL 122 & PMLS & $17 / 18$ & 15.38 & 0.63 & 26 \\
\hline DL 143 & PMLS & $20 \mathrm{a}, 20 \mathrm{~b}, \mathrm{DLS}$ & 0 & 0 & 0 \\
\hline DL 113 & \multicolumn{2}{|l|}{$17,18 \mathrm{R} ; 17 / 18, \mathrm{~L}$} & 11.7 & - & 26 \\
\hline DL 51 & \multicolumn{2}{|l|}{$21 \mathrm{a} / \mathrm{PMLS}, \mathrm{R}+\mathrm{L}$} & 1.04 & 0.14 & 1 \\
\hline DL 63 & \multicolumn{2}{|c|}{ 21a/PMLS, R; 17, 18, L } & 0.34 & 0.48 & 2 \\
\hline DL 126 & 17,18 & $17 / 18$ & $6,^{b} 10.6^{c}$ & - & $8, " 21^{\circ}$ \\
\hline DI. 127 & 17,18 & 18 & $12,^{b} 14.42^{c}$ & - & $24,31^{\circ}$ \\
\hline
\end{tabular}

Callosal neurons projecting to ipsilateral areas $(\mathrm{CC}+\mathrm{Assoc})$ are expressed as a percentage of all callosal neurons (CC) or of association neurons (Assoc). Total number of $\mathrm{CC}+$ Assoc sampled is also shown. Counts were restricted to regions with the highest packing density of association neurons (see Appendix). The experiments DL 52, 53, and 112 (see Table 1) were not quantitatively analyzed. They gave, however, results similar to those for the other animals with similar injection locations.

${ }^{a}$ These are probably underestimates, since counts are from near the peaks of association neuron density (see Appendix).

${ }^{n}$ Late (DY) injection.

'Early (RL) injection.

2) could be relabeled in DL 120, where the late injection (Fig. 10 ) went more medial than in DL 124 , was probably restricted to area 17 , and was very similar to that in DL 106 . Indeed, the radial and tangential distributions of DY-labeled neurons in these two animals were also very similar.

The highest number of transitorily callosal neurons $(15.38 \%$; Table 2) was relabeled in DL 122 by a DY injection involving areas 17 and 18 and their underlying white matter (Figs. 2, 10). This injection also yielded the highest density of DY-labeled neurons observed in this group of animals. DL 122 had also received an RL injection into area 18 , simultaneously and on the side of the FB injection in PMLS. Some of the RL-labeled neurons were relabeled by DY, but no neurons were found to be labeled by the three dyes although the three populations overlapped extensively. This was not surprising, since the neonatal projections from 17 to contralateral PMLS and 17-18 originate from different neuronal sets (Innocenti and Clarke, 1983, 1984b).

In DL 143, five injections were placed into areas $20 \mathrm{a}, 20 \mathrm{~b}$, and DLS. As in DL 145, which had been similarly injected, retrograde labeling was restricted to near the fundus of the splenial sulcus and no relabeling of callosal neurons was obtained.

Table 2 summarizes the result of this group of experiments. The transitorily callosal neurons to PMLS, as those to 17 and 18 , tend to project later to $17-18$ much more frequently than to other ipsilateral areas.

Neonatal injections of various visual areas and of contralateral areas $17-18$ or PMLS

These experiments were meant to determine whether at birth transitorily callosal neurons send an axon collateral to ipsilateral areas, and in particular to those they will project to after elimination of the callosal axons.

This appears indeed to be the case. Double-labeled neurons in the medial part of left area 17 were found in the kittens DL 112 and 113, in which FB and DY had been injected, respectively, in the right and left areas 17-18, including the underlying white matter. Only in DL 113 (Figs. 13,14) was the rate of double labeling quantified: $11.7 \%$ of the transitorily callosal neurons in area 17 were also labeled by the DY injection in ipsilateral area 18 . This proportion is very similar to that found in DL 114, which had received a similar combination of injections but whose area 18 was injected on day 40 (see above). The radial distribution of the double-labeled neurons was similar to that found in kittens in which the neurons were relabeled by late 18 injections (e.g., DL 114 and 124).

Only a few transitorily callosal neurons in either right or left area 17 were double-labeled after bilateral PMLS (and 21a) injections (DL 51 and 52). In DL 51 (Fig. 13) only one such neuron was found, representing about $1 \%$ of the population of transitorily callosal neurons to PMLS examined (Table 2). Around the time of birth, area 17 seems also to contain very few transitorily callosal neurons projecting both to contralateral 17-18 and to ipsilateral PMLS. Only two such neurons were found in DL 63 (Figs. 13, 15), representing $0.34 \%$ of the population of callosal neurons examined (Table 2).

\section{Stability of neonatal collaterals to ipsilateral visual areas}

In order to assess whether the transitorily callosal neurons that also project to ipsilateral area 18 around birth maintain the projection to this area after elimination of the callosal collateral, 

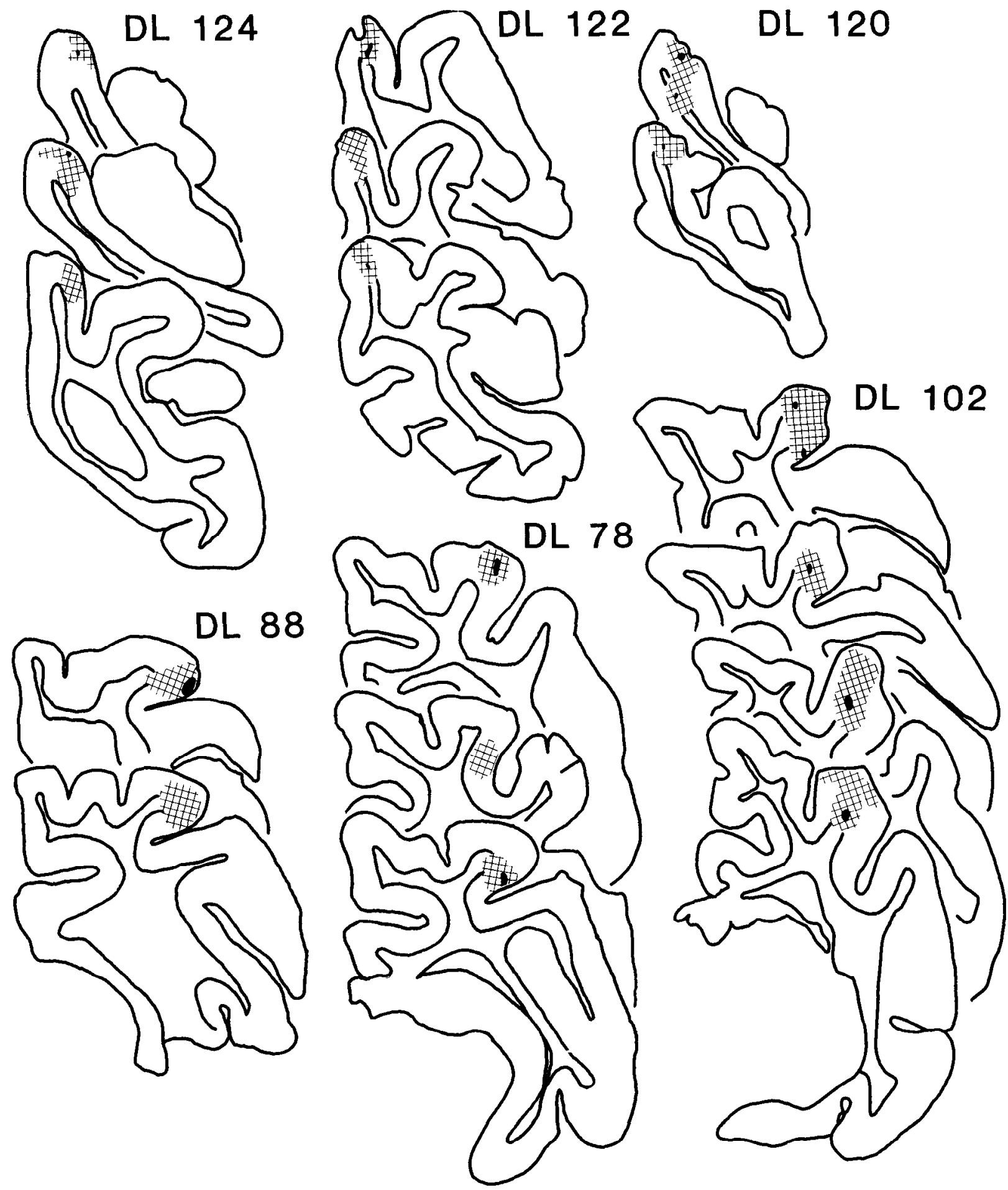

Figure 10. Sites of late DY injections in a selected group of kittens with neonatal FB injections in contralateral areas PMLS. All conventions as in Figure 3.

the following experiment was performed. Three kittens (DL 125, $126,127)$ received injections of $F B$ in areas 17 and 18 of the right hemisphere and of RL in the left area 18 at day 3 . In the second postnatal month, the latter area was reinjected with DY as close as possible to the RL injection (Table 1). The precise boundaries of the RL injection sites are difficult to establish since this dye tends to disappear from the extracellular space. Judging from the residual cellular labeling, though, the injections appeared to have been confined to the gray matter in DL 126, while in DL 125 and 127 they probably extended somewhat into the white matter. The DY injections extended through all layers of area 18 , reaching just to the white matter, and extensively overlapped with the RL injections (Fig. 13).

In all these animals, neurons labeled with different tracers were intermingled over wide portions of the left area 17.

Seven sections through the left areas 17 and 18 , spaced 180 $\mu \mathrm{m}$ apart, were charted in DL 127 (Figs. 2, 13, 16), the animal in which most extensive overlap of DY and RL injections was achieved. The proportion of FB neurons also labeled with RL or with DY was estimated in slightly different parts of each 
DL $78: 3,41,47$

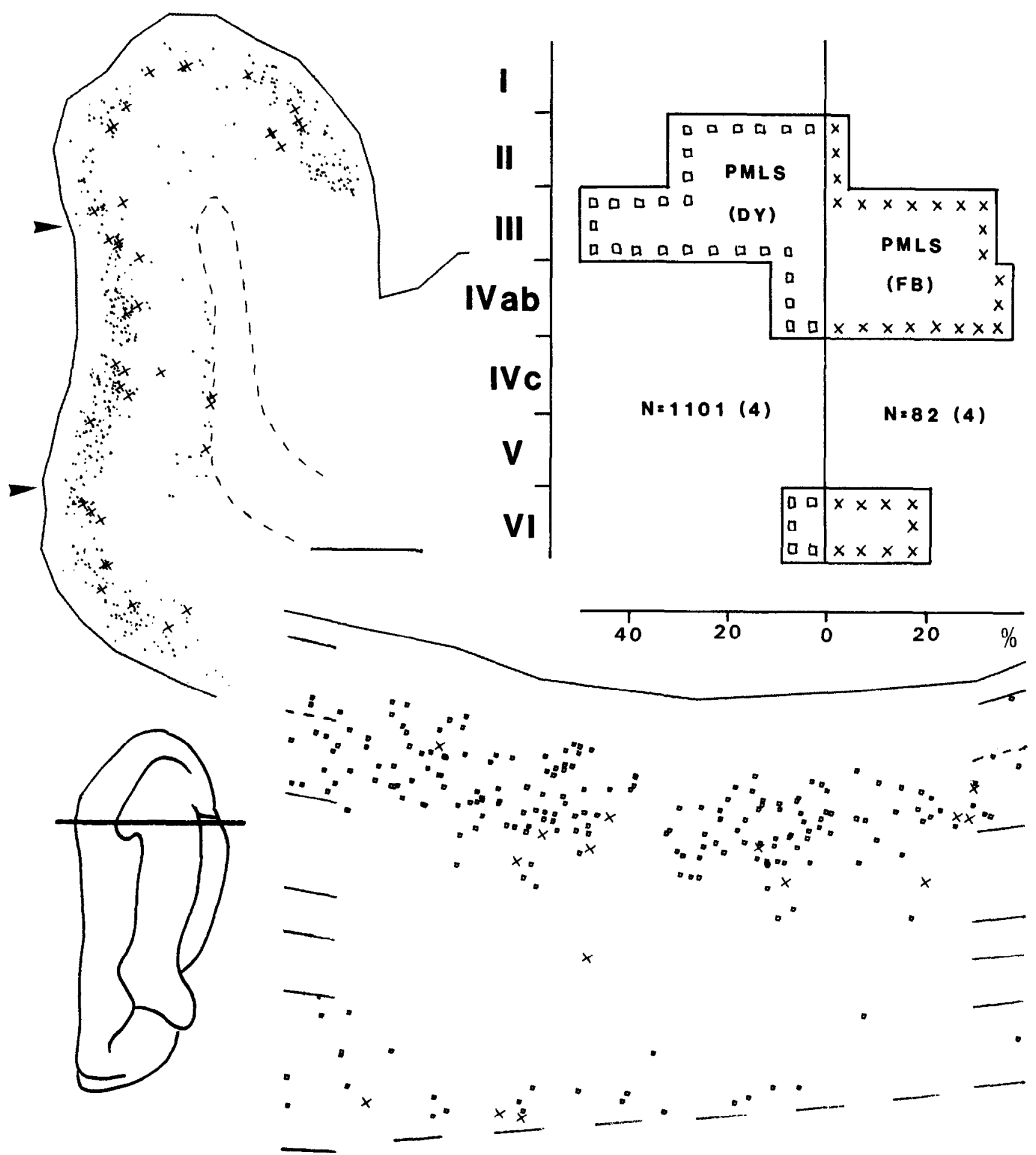

Figure 11. Callosal neurons (crosses) in area 17, labeled by neonatal FB injections in contralateral area PMLS and association neurons (squares or dots) labeled by late DY injections in ipsilateral area PMLS (see Fig. 10) in DL 78. All conventions as in Figures 4 and 5.

section (Fig. 16) since the peak densities of FB- and DY-labeled neurons did not coincide (see Appendix). The callosal neurons relabeled by the early area 18 injection (Table 2) were 31 out of $215(14.4 \%)$, while those labeled by the late area 18 injection were 24 out of $200(12 \%)$. Both figures are similar to those found, respectively, after early area 18 injection and short survival (e.g. DL 113; Table 2) or after late injection of this area (e.g., DL 98 or DL 114; Table 2).

A total of four FB-labeled neurons, concentratcd in three of the seven sections, were also labeled with DY and RL. In these 


\section{DL $124: 3,40,46$}

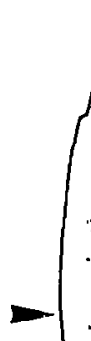

(1)

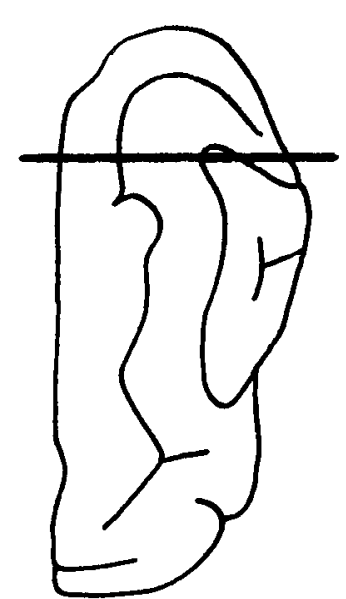

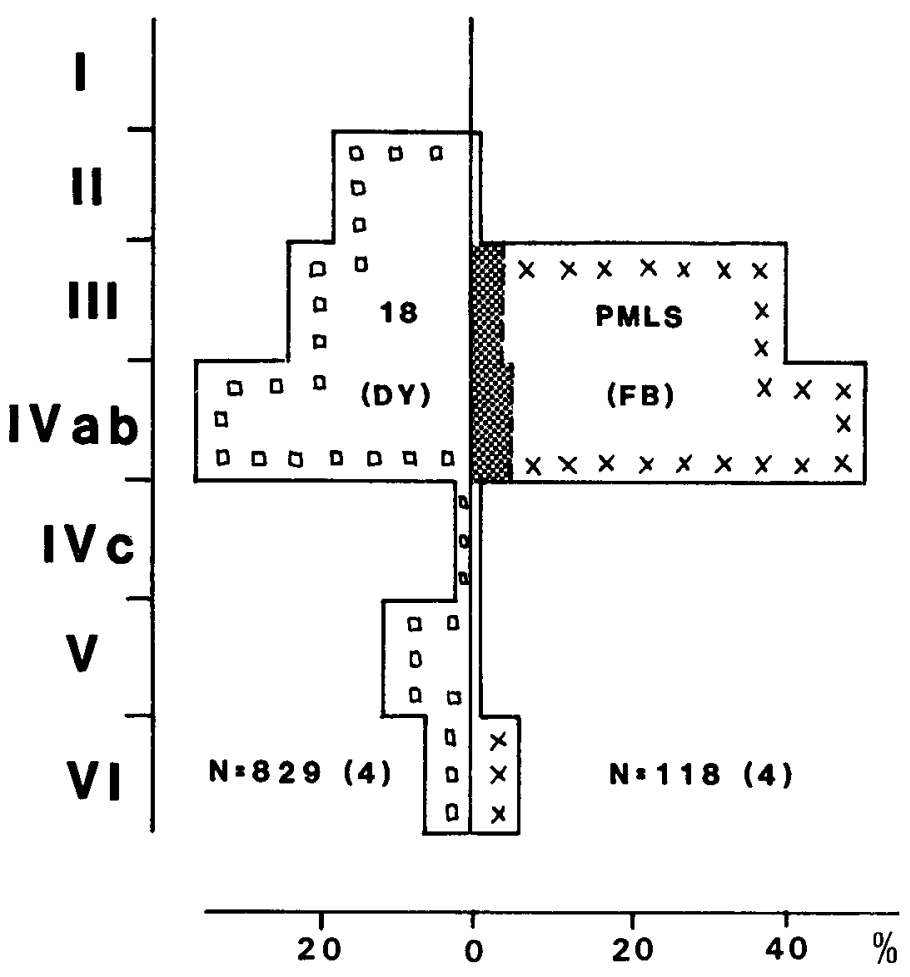

$\begin{array}{rll}x & x \\ x & 1 & 1\end{array}$
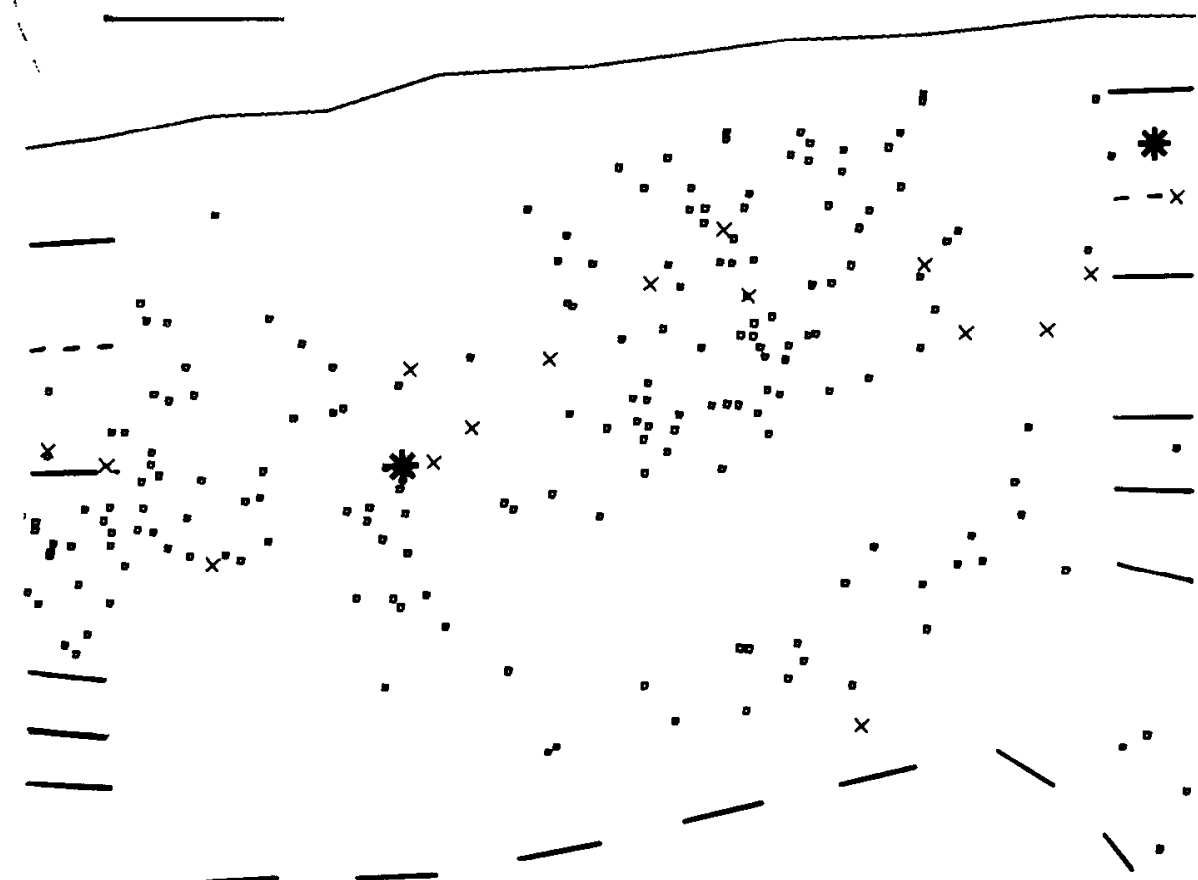

Figure 12. Callosal neurons (crosses) in area 17, labeled by neonatal FB injections in contralateral area PMLS and association neurons (squares or dots) labeled by a late DY injection in ipsilateral area 18 (corresponding to the rostral-most injection in Fig. 10) in DL 124. Double-labeled neurons are shown by asterisks. All conventions as in Figures 4 and 5. 


\section{51}
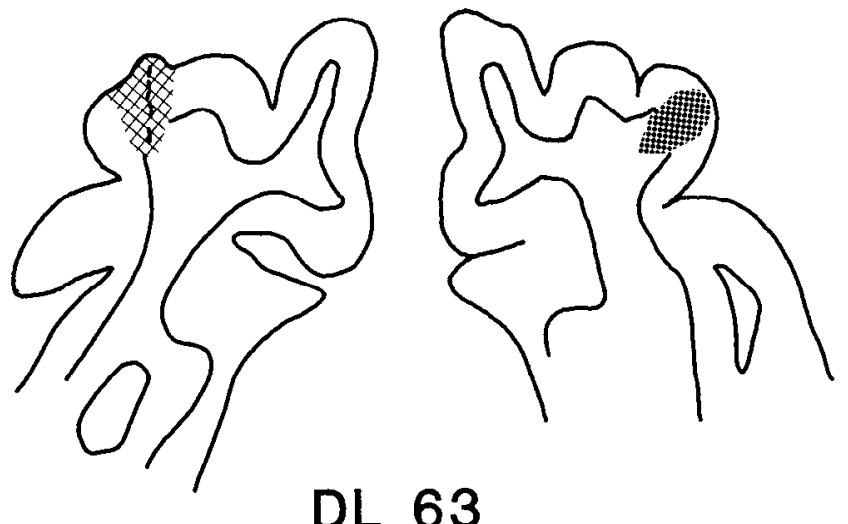

DL 63
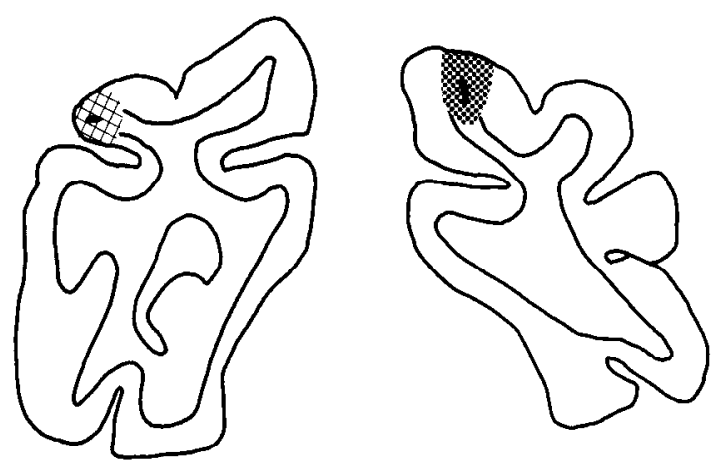

DL 113
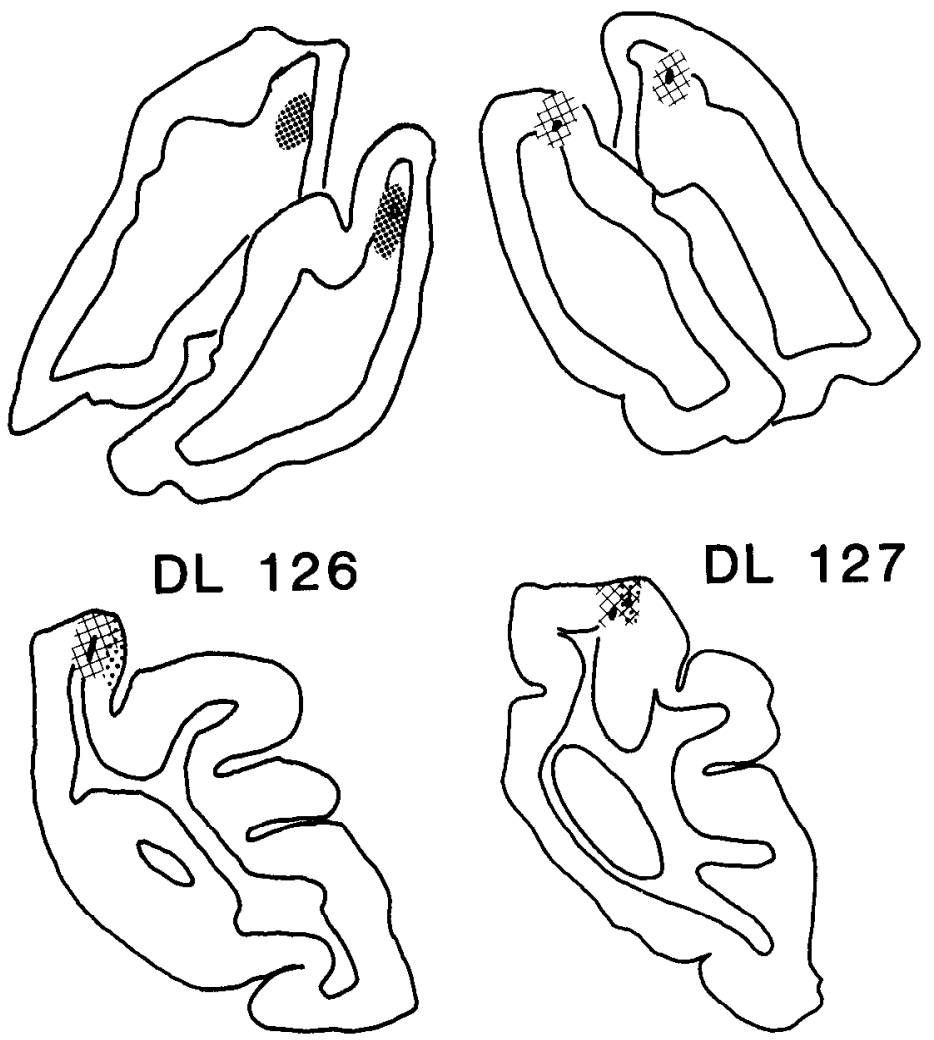

Figure 13. Injection sites in three kittens (DL 51,113,63) that received carly FB (dark shading) and DY or NY (light shading) injections in different areas. Early RL (dotted) and late DY injection sites in area 18 of two other kittens (DL 126,127) with neonatal FB injections in contralateral areas 17 and 18. In sections of DL 127 caudal to the one shown here, both DY and RL injections reached the white matter. All conventions are as in Figures 3 and 10, but in DL 51 the positions of right and left hemisphere are mirror-reversed.

same sections, we also charted 738 DY-labeled neurons, some of which were also RL-labeled. ${ }^{1}$

In DL 126 (three sections charted; Fig. 2), the ratio of relabeling of transitorily callosal neurons was lower than in DL 127 , but still within the range found in other animals with either early or late 18 injections (Table 2). In these three sections, three FB-labeled neurons were also labeled by RL and DY.

In DL 125 , the RL and the DY injections overlapped very little, as did the territories containing neurons retrogradely labeled by either dye. No FB-labeled neurons were found to be also labeled by RL and DY, although some were double-labeled by one or the other tracer.

Although the number of triple-labeled neurons in these experiments is definitely too small to allow any firm conclusion, we decided to calculate the proportion of DY neurons and of $\mathrm{DY}+\mathrm{FB}$ neurons relabeled by $\mathrm{RL}$ as a way to test the hypothesis that some transitorily callosal neurons may grow an association axon only after eliminating the callosal one (see Appendix). In DL 127, RL labeled $16 \%$ of the FB+DY neurons and $12.6 \%$ of the DY neurons in the same sections. In DL $126,37 \%$ of the DY + FB neurons and $21 \%$ of the DY neurons were labeled with $\mathrm{RL}$. Differences in relabeling ratios across animals were prob-

\footnotetext{
'The proportion of DY neurons also labeled by RL increased progressively from regions with the lowest density of $\mathrm{RL}$ labeling (near the crown of the lateral gyrus) to the regions with the highest density of RL labeling (near the fundus of thc suprasplcnial sulcus), where more than $50 \%$ of the DY-labeled neurons were also RL-labeled. This distribution of double-labeling ratios conforms to the theoretical predictions discussed in the Appendix, and justifies the sampling strategy adopted throughout this paper, i.e., to estimate the proportion of relabeling as close as possible to the regions with the highest density of neurons labeled by one or the other tracer.
}

ably due to the fact that in DL 126 the sampling was closer to the regions of maximal density of RL-labeled neurons than in DL 127.

In both animals, the differences in the RL labeling ratios were the opposite of what the regrowth hypothesis would have predicted (see Appendix). These differences are explicable if a fraction of the DY-labeled neurons sent their axon to area 18 too late to be labeled by the RL tracer (see Appendix). Other evidence also supports the view that at the time of RL injection, the 17-to-18 projection had not yet fully developed (see Discussion).

\section{Discussion}

\section{Tracing neural connections over time}

Most neuroanatomical techniques provide a static picture of neural organization and are inadequate to deal with its modifications. To take an extreme example, the question of whether the connections of a given neuron are stable over time usually cannot be answered directly. Although in the normal adult brain this may not be a real problem, it is a crucial one in the developing or diseased brain. To overcome this limitation, some of the retrograde fluorescent tracers originally introduced for studying the collateralization of axons (Bentivoglio et al., 1979, 1980; Keizer et al., 1983) have recently been used in neurodevelopmental studies (Innocenti, 1981). In particular, the property of FB, and also of True Blue and Granular Blue, of providing a long-lasting retrograde labeling of neuronal somata has allowed monitoring the fate of neurons that project temporarily to a certain target in development (Innocenti, 1981; Innocenti 


\section{113:0,5}

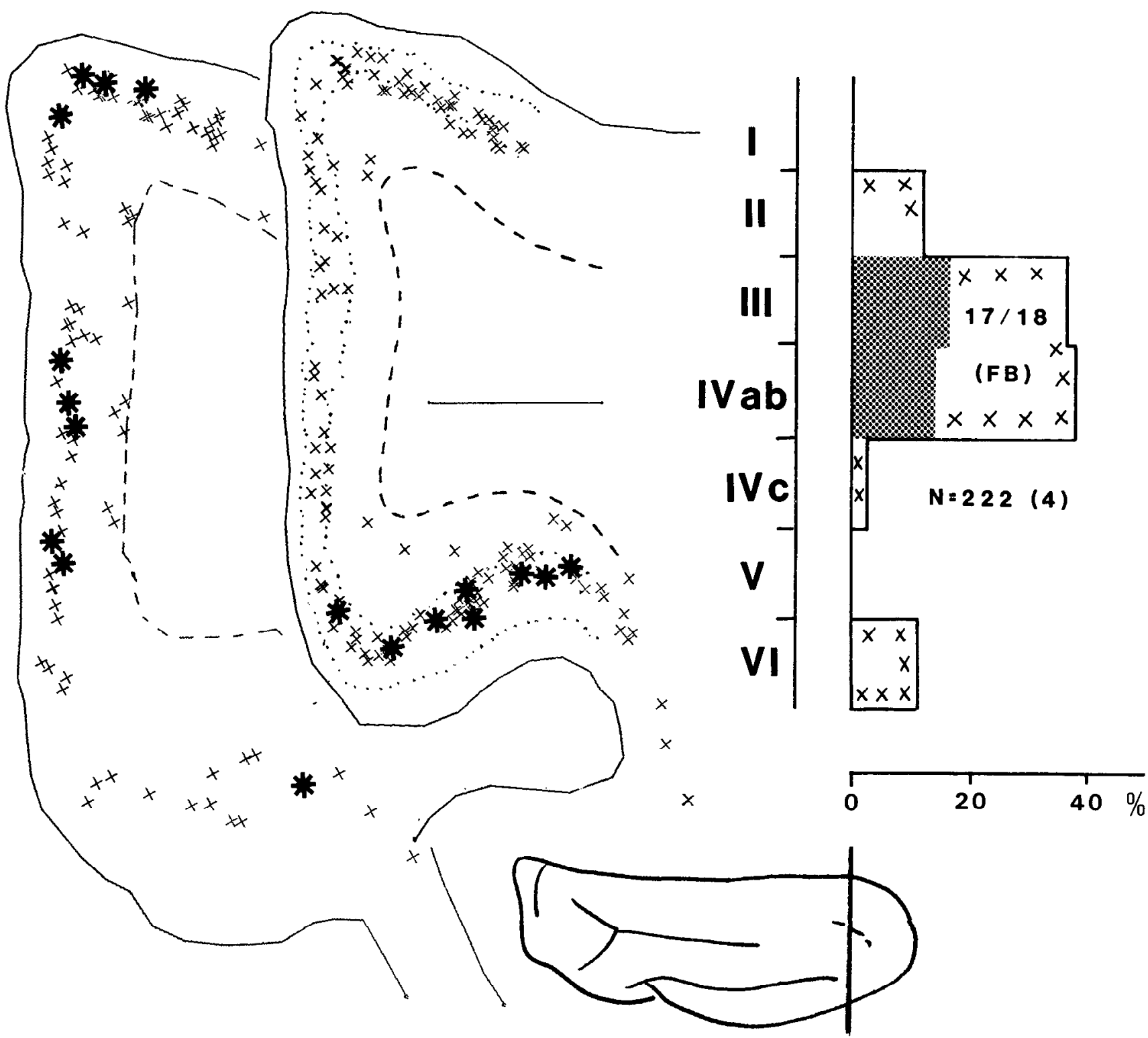

Figure 14. Callosal neurons in area 17 labeled by neonatal FB injections in contralateral areas 17 and 18 (crosses) and by DY injections in ipsilateral area 18 (asterisks) in DL 113 (see Fig. 13). The heading indicates age of the kitten at the time of injection and of perfusion. Only FBand FB+DY-labeled neurons were charted, but the upper and lower borders of DY labeling in layers II-IV are marked by dots in one of the sections. The two sections are at the level shown in the brain insets, $360 \mu \mathrm{m}$ apart. All other conventions as in Figures 4 and 5.

and Clarke, 1984a; Ivy and Killackey, 1982; O'Leary et al., 1981; Stanfield et al., 1983).

Now a new tracer, the rhodamine-conjugated latex microspheres, has become available (Katz et al., 1984), which also provides long-lasting labeling of perikarya. Because its excitation and emission wavelengths are different from those of the blue tracers, this tracer can be combined with the latter in various experimental paradigms, considerably expanding the range of questions these techniques can handle. In the two-dye experiments used until now, a single long-lasting tracer was injected at an early age, followed after several weeks survival by injection of a second tracer in the same (homothetic relabeling) or in a different (heterothetic relabeling) structure, in turn followed by a new, shorter survival, and perfusion. In this study we applied a similar paradigm, but two long-lasting tracers were injected early to try to monitor the stability of axonal collaterals in the developing brain.

These long-lasting tracers have drawbacks. First, although apparently well tolerated by retrogradely labeled neurons, they can display dose-dependent toxicity at the injection site. With FB and Granular Blue, especially the latter (Innocenti, 1981), we have occasionally observed large lesions in the white matter. $\mathrm{RL}$ may be less toxic. In our limited experience with this tracer we have never observed lesions as severe as with FB or Granular 

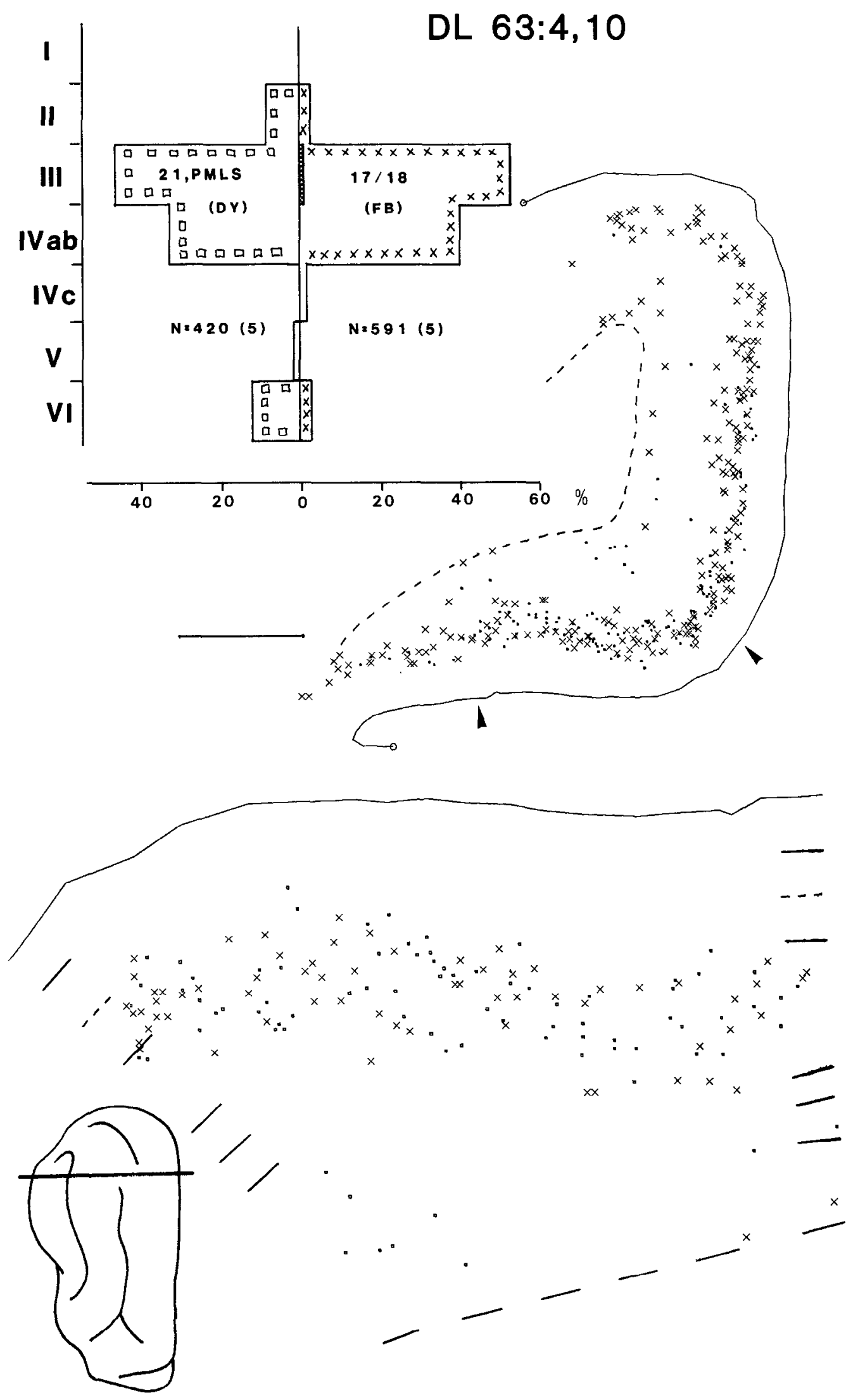

Figure 15. Neurons in area 17 labeled by neonatal FB injections in contralateral areas 17 and 18 (crosses) and by a DY injection in ipsilateral areas $21 \mathrm{a}$ and PMLS (squares or dots) in DL 63 (see Fig. 13). All other conventions as in Figures 4 and 5. 


\section{DL $127: 3,40,44$}

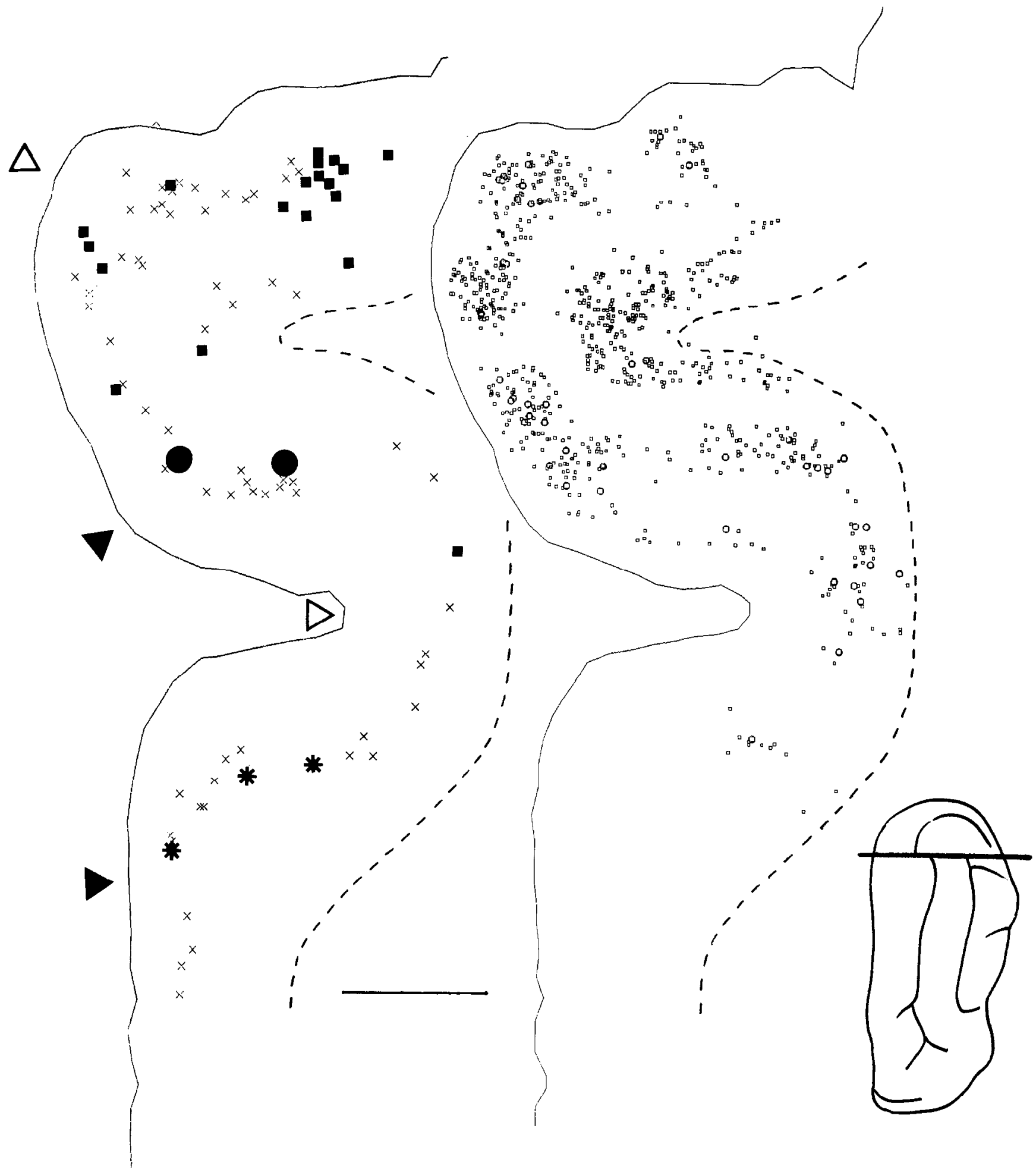

Figure 16. Callosal neurons in area 17 (crosses) labeled by neonatal FB injections in contralateral areas 17 and 18 and association neurons (squares) labeled by late DY injections in ipsilateral area 18, which had also received a neonatal RL injection. Neurons labeled by FB and DY (callosal neurons projecting to ipsilateral area 18 during the second postnatal month) are shown by filled squares. Neurons labeled by FB and RL (callosal neurons also projecting to ipsilateral area 18 at birth) are shown by asterisks. Neurons labeled by FB, DY, and RL (callosal neurons projecting to ipsilateral area 18 at birth and during the second postnatal month) are shown by the large filled circles. Neurons labeled by DY and RL (neurons projecting to ipsilateral 18 at birth and during the second month) are shown by small open circles. The two charts are from the same section. Rates of DY labeling of callosal neurons (Table 2) were calculated for part of the section between open arrowheads in this section and in corresponding portions of the other six sections; rates of RL labeling of callosal neurons (Table 2) were calculated for part of the section between filled arrowheads in this section and in corresponding portions of six other sections (for further explanation see text). Other conventions as in Figures 4 and 5. 
Blue. Obviously, the lesion at the injection site could induce reactions such as death or collateral sprouting in the neurons whose axons were destroyed. Although brains with large lesions at the injection site were discarded, on superficial inspection we did not notice in these brains important modifications of the distribution of transitorily callosal neurons, certainly not their death.

The second serious drawback is that certain retrograde traccrs can diffuse out of the neurons they were transported to and secondarily label other neurons that do not project to the structure injected. This phenomenon has restricted the use of some tracers; this is particularly true of Nuclear Yellow, which finally led to its substitution with DY for tracing axon collaterals in the adult (Keizer et al., 1983). Although DY diffuses out of neurons in small amounts and slowly, its usefulness as a longlasting tracer remains dubious. On the contrary, the clearest sign of outward diffusion of the tracers (i.e., the labeling of glia around filled neurons or axons, which was only rarely observed with FB or Granular Blue) was never observed with RL, although it must be noted that the morphology of weakly labeled elements cannot be easily identified with this tracer (see Materials and Methods). A more subtle source of artifacts could, however, be the presence of gap junctions, permeable to certain molecules, between neurons. Such junctions have been demonstrated in developing rat neocortex (Connors et al., 1983) with intracellular injections of Lucifer Yellow. Theoretically at least, the RL microspheres are much too large to cross gap junctions (Simpson et al., 1977). Furthermore, the distribution of retrogradely labeled neurons remains the same within large ranges of survival times. In particular, the clustering of labeled neurons typical of transneuronal labeling after the intracellular injection was not observed.

A third drawback is that the tracers are cleared away slowly not only from the neurons that took them up, but also from the injection sites. Thus, they remain available for uptake by axons that reach a target long after this was injected. Eventually, most of the neurons whose axons arrive at a target between injection and perfusion will be visualized, although the latest arrivers may be missed either because of the slow uptake/transport of the tracers or because of their clearance from the injection site. That the latter can play a role is shown by the fact that when sufficiently small amounts of tracers are injected, late-projecting neurons can be missed or recognized by their lighter labeling. For example, injections of FB in the visual cortex of newborn rodents usually label callosal neurons in all layers, although at the time of injection only the infragranular layers have already projected into the corpus callosum (Clarke and Innocenti, unpublished observations); however, by reducing the size of injections, we have succeeded in decreasing, or even avoiding, the labeling of the late-projecting supragranular layers. In this study these considerations become important for interpreting the triple-labeling experiments (see below).

A fourth drawback is that, as originally reported (Bentivoglio et al., 1980), not all the tracers may be equally transported over long distances. This may explain the failure in labeling of the transitory cerebrocerebellar projections with True Blue (Panneton and Tolbert, 1984).
Finally, the quantification of the double or triple labeling presents important sampling difficulties (see Appendix).

\section{Neuronal death}

In principle, the long-lasting retrograde fluorescent tracers should allow one to decide whether elimination of a given projection is due to neuronal death. However, this remains a difficult task, unlcss ncuronal death is massive (e.g., Bunt et al., 1983; Insausti et al., 1984) or else the total number of projecting neurons can be calculated before and after neuronal death (e.g., O'Leary and Cowan, 1982). Neither condition applies to the transitory projections from cerebral cortex. In the present study, a slightly higher proportion of transitorily callosal neurons is labeled in layer VI after short than after long survivals, following neonatal injections. This could mean that the transitory callosal projection from layer VI is, at least in part, eliminated by neuronal death. Alternatively, the proportion of neurons projecting into the corpus callosum from supragranular layers may still be increasing postnatally. The occurrence of neuronal death in the granular and supragranular layers would also have gone completely unnoticed in this study.

Relative counts of labeled versus unlabeled neurons following different survivals after injection of long-lasting fluorescent tracers may help to decide whether death of callosal neurons occurs in development. This, of course, requires strong criteria to distinguish neurons from glia in the immature brain, and a way to estimate tracer-induced neuronal death and tracer clearance as possible sources of artifact.

It is of course possible that neuronal death contributes to the elimination of transitory projections from cerebral cortex. Neuronal death has been reported to occur in the neocortical white matter (Luskin and Shatz, 1985) and also in the gray matter, although much of the latter evidence is, in our opinion, inconclusive for lack of appropriate quantification and/or stringent criteria for identifying dying neurons and distinguishing them from dying glia.

\section{Reorganization of axonal projections}

The present experiments confirm that the elimination of the transitory callosal projections from area 17 is due largely, and possibly entirely, to elimination of transitory axons rather than neuronal death. Furthermore, direct evidence now supports the hypothesis (Innocenti, 1981) that transitorily callosal neurons of area 17 will eventually establish association projections. Two mechanisms could explain how this rededication to a target occurs in development, i.e., (1) selection of early, multiple collaterals and (2) late axonal regrowth (see introduction). The first hypothesis is undoubtedly strengthened by the present results. Transitorily callosal neurons in area 17 of the cat can be identified with absolute certainty from their location; in particular, there are no callosal neurons medial to the suprasplenial sulcus, where many double-labeled neurons were found (Figs. 4, 5, 8, $14,16)$. In the adult, most of this area does not project into the corpus callosum (Innocenti, 1980; Innocenti et al., 1985; Segraves and Innocenti, 1985) Furthermore, some transitorily callosal ncurons in arca 17 can also be labeled by injection in ipsilateral 18 before and after they have eliminated their callosal

\footnotetext{
Figure 17. Summary of laminar distributions of four sets of efferent neurons in area 17 after perinatal injections and different survivals. Each histogram was constructed by averaging across animals the relative contribution of a layer to a given efferent set; segments extending from each column are SD bars. Data from individual animals were shown in the preceding figures or derive from similarly sampled experiments. Animal codes, type of projection, and total number of neurons for each histogram are indicated. The bottom left histogram (interrupted contour) also shows the radial distribution of RL-labeled callosal neurons in the experiment DL 122. In this histogram and the one next to it, the column corresponding to layer IVab is subdivided into two cases; the left $(a)$ corresponds to the fraction of neurons found in the upper half of layer IVab; the right (b) the fraction of neurons in the lower half of layer IVab.
} 
EARLY INJECTIONS, Short survivals

TRANSITORY CC

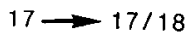

(DL $48,49,63,113)$

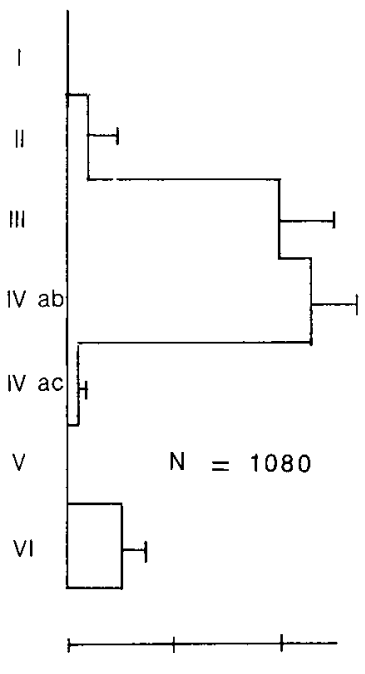

0
TRANSITORY $C C$

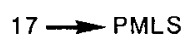

(DL $48,49,51$ )

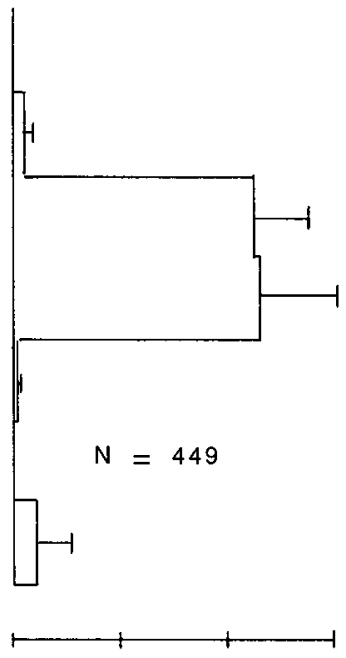

0
$17 \rightarrow-18$

(DL $35,48,116)$
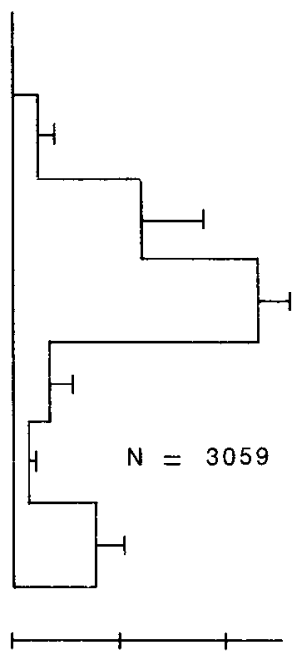

0
$17 \rightarrow$ PMLS, 21 a

(DL 51,63)

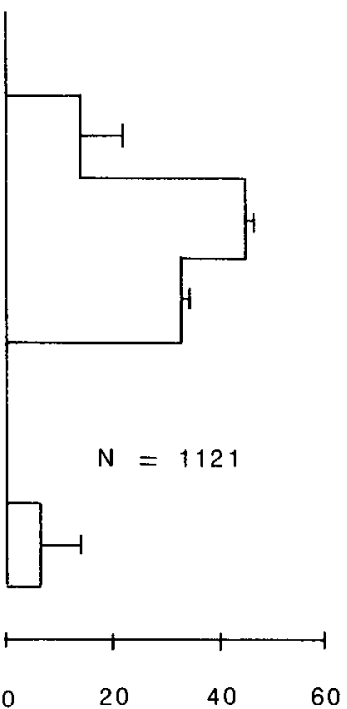

EARLY INJECTIONS, Long survivals

LATE INJECTIONS

TRANSITORY $\mathrm{CC}$

$17 \rightarrow 17 / 18$

(DL $97,98,100$,

$101,105,106,114,122]$

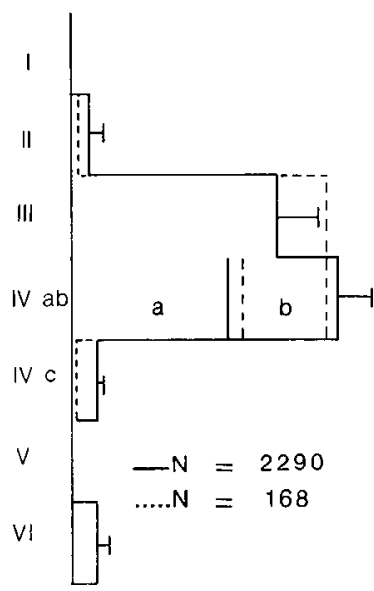

TRANSITORY CC
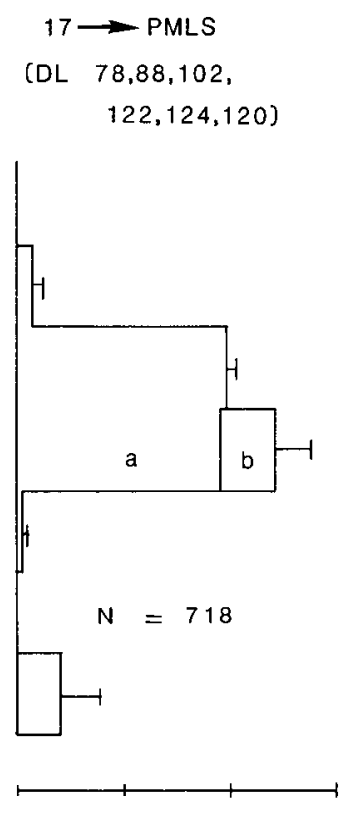

0

20

40
$17 \rightarrow 18$

(DL 114,124)
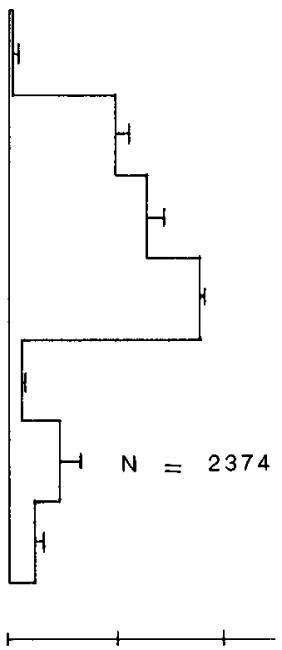

0
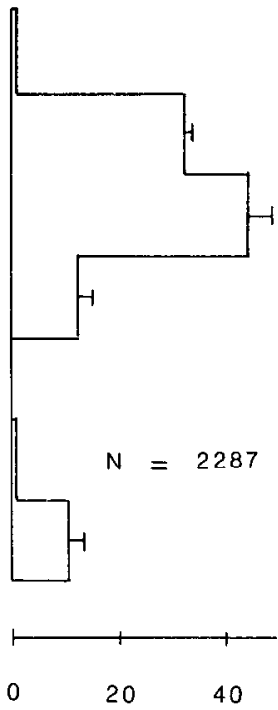

$\%$ LABELED NEURONS

Note that each efferent set of neurons has a different and characteristic radial profile in the older kittens (bottom row of histograms). Transitorily callosal neurons have a similar distribution in young and older kittens (compare top and bottom left histograms), but in both age groups callosal neurons to PMLS tend to be proportionately less numerous in layers II, IVbc than callosal neurons to areas $17-18$. In younger kittens, the relative contribution of layer II to the projection to ipsilateral 18 or PMLS/21a is less than in the older kittens, suggesting that this layer is still forming its projections. The 17-to-18 association neurons seem relatively more common in the deep layers at birth than during the second month. This, however, probably reflects the fact that in the young animals, injection sites involved the white matter (as intended), which may have labeled en passage neurons projecting to other cortical areas or to subcortical structures. 
axons. This finding seems to eliminate the uncertainties remaining after previous work (see introduction). Even with the present evidence, however, it would be premature to conclude that the occurrence of collateral selection is fully proven-nor can the regrowth hypothesis be ruled out. One difficulty is that RL, not unlike FB (see above), remains available for uptake for an unknown length of time after injection. For example, although few neurons in layer II of area 17 can be labeled at birth by area 18 injections, they become labeled by perinatal RL injections followed by long survival (Innocenti et al., unpublished observations). It is therefore possible that somc transitorily callosal neurons may reach the ipsilateral RL injection site and take up the tracer only after they have eliminated their callosal axon. And, of course, the above-mentioned finding that new axons are added to the 17-to-18 associational projection postnatally, i.c., while callosal axons are being climinated (Innocenti et al., unpublished observations), strengthens the lateregrowth hypothesis. An additional difficulty is that transitorily callosal neurons may grow an axon collateral to ipsilateral area 18 before the callosal axon is eliminated but after its fate has already been irreversibly decided.

\section{Selectivity in the development of neocortical connections}

Transitorily callosal neurons in area 17 could be relabeled by injections in ipsilateral areas 17 and 18, before and/or after elimination of most of the transitory callosal axons. Little or no relabeling of callosal neurons was obtained in the eight experiments in which areas 19,21a, and PMLS, which also receive from ipsilateral area 17, were injected before or after elimination of most of the transitory callosal axons. Although several factors can probably lower the estimated frequency of double labeling (see below), it is unlikely that they are responsible for the nearly complete failure at relabeling callosal neurons in eight experiments. In particular, the topographical location of the injections was adequate since in all these experiments FB-labeled transitorily callosal neurons and DY-labeled neurons were intermingled.

Thus, the most likely explanation of our findings is that juvenile callosal neurons are very selective in the choice of their final target. ${ }^{2}$ This choice is probably restricted and conditioned by the target selectivity neurons express before birth. Adult callosal neurons still express a similar selectivity since none of them projects to ipsilateral PMLS, although most of them have collaterals within area 17 , and some of these collaterals are so long that they may reach area 18 (Innocenti, 1980). What is the nature of this target selectivity? The corticocortically projecting neurons in area 17 probably do not choose their target on the ground of specific affinity for an area, irrespective of its side. In fact, contrary to the predictions of this hypothesis, area 17 neurons projecting transitorily to contralateral PMLS do not form their later projections selectively to ipsilateral PMLS, but also to areas 18 and 17.

Why then do transitorily callosal neurons project to area 18 rather than to any of the other 17 visual areas? The critical factor may be one of the following features of the 17-to-18 association projection. (1) Areas 17 and 18 are close to each other. The distance of the later target may be important, irrespective of whether this is chosen by selection of collaterals or late growth. Indeed, there may be constraints on the size of the axonal arbor a neuron can establish (Schneider, 1973) or on the distance a late-growing axon can travel. (2) Transitorily callosal

\footnotetext{
${ }^{2}$ Experiments elucidating the fate of transitory projections from visual cortex to spinal cord in the rat were published (O'Leary and Stanfield, 1985) after submission of this paper. The results show that visual cortical neurons projecting transitorily to the spinal cord establish permanent projections to superior colliculus and pons and not to the contralateral hemisphere. Thus, these findings tend to support the arguments on the specificity of reorganization of neocortical projections developed here.
}

neurons (either to $17 / 18$ or to PMLS) are similar in their radial distribution to the association neurons to 18 . The bulk of both sets of neurons is in layer IV and III, while projections to other visual areas originate, on average, more superficially in the cortex. Thus, as we have argued elsewhere (Innocenti and Clarke, 1984b), birth date of cortical neurons, which is reflected in radial position, may condition their choice of a target. Two other arguments further support this interpretation. First, different sets of corticocortically projecting neurons in area 17 , each defined as projecting to a different area, have different and charactcristic radial distribution profiles. These differences are even more subtle and precise than previously reported (Gilbert and Kelly, 1975; Keller and Innocenti, 1981; Segraves and Innocenti, 1985; Symonds and Rosenquist, 1984b). Second, the radial distribution profiles are acquired early, probably as soon as the projections are formed. These points can be appreciatcd in the individual cases described in the Results. In addition, Figure 17 integrates the results obtained from different animals concerning the radial distribution of four sets of efferent neurons around birth and during the second postnatal month.

A point worth stressing is that the early specificity, whatever its nature, probably determines the development of the connections relatively, not absolutely. In fact, the transitory callosal projections can be stabilized by a variety of experimental manipulations (see introduction). Of course, it would be interesting to assess whether neurons whose callosal projection was abnormally stabilized had also modified their ipsilateral connectivity.

In the present experiments, only a fraction of the transitorily callosal neurons could be relabeled. In the best cases, this fraction is slightly above $15 \%$ of the FB-labeled population, which in turn may underestimate the original population of transitorily callosal neurons since some neurons may have died or may have eliminated the neonatally injected tracer. It is, however, more probable that the figure of $15 \%$ underestimates the proportion of transitorily callosal neurons that establish permanent connections in ipsilateral areas 17 and 18. First, each tracer may have failed to label a fraction of the neurons effectively projecting to the injection site. Second, double-labeled neurons are more difficult to detect than single-labeled ones; the DY-labeled nucleus may be out of the plane of section, and occasionally the $\mathrm{FB}$ gives to the nucleus a silvery-bluish color that interferes with the detection of the DY. Finally, in each experiment only a small part of ipsilateral areas 17 and 18 were reinjected. While this decreases the danger of spurious positive results, it may also decrease the probability of relabeling.

Even so, it is difficult to escape the conclusion that many transitorily callosal neurons must form permanent connections to a target we failed to inject. As callosal neurons are mostly located in granular and supragranular layers, we can probably exclude subcortical structures as a possible target. Subcortical structures in fact seem to receive exclusively from infragranular layers. Of the cortical targets of area 17 (Montero, 1981; Symonds and Rosenquist, 1984a), the only one not extensively explored in these experiments was area 17 itself. This was, because the intra-areal labeling resulting from tracer injections is difficult to interpret. These injections are usually surrounded by a halo where most neurons are labeled, although not necessarily through their axons. It is highly probable that some transitorily callosal neurons eventually form intra-areal projections. A1though most of the transitorily callosal neurons are pyramids, pyramids with local axons have been described with the Golgi technique (Sholl, 1955) and with intracellular injection of tracers (Gilbert and Wicscl, 1983). Furthermore, according to Sholl (1955-see Table 1), these neurons are most common in layers III and IV, just as are transitorily callosal neurons. Cajal (1911) already reported that in young brains, pyramids can transform into intrinsic neurons when their axon is experimentally tran- 
sected. This dramatic example of neuronal plasticity would then be the expression of a transformation of cellular morphology commonly occurring in normal brain development.

\section{Appendix}

\section{Quantification of multiple labeling}

\section{Two-dye experiments}

Consider a structure A projecting topographically to two other structures $B$ and C. An injection of retrograde tracer in a limited region of B or $C$ will retrogradely label the highest density of neurons at the point of A that projects to the core of the injection site, and the density will progressively decay away from this peak (for such a distribution of retrogradely labeled callosal neurons, scc Innocenti, 1980-Fig. 12). The decay function must obviously depend on the convergence/divergence of the projection but also on the progressive failure of uptake and/or transport of the dye at increasing distances from the center of the injection. When two tracers are used, a certain proportion of neurons in A projecting through bifurcating axons to both $\mathrm{B}$ and $\mathrm{C}$ may be labeled by a tracer injected in $\mathrm{B}$ but not by the second tracer injected in $\mathrm{C}$ because their terminals are too remote from the core of the latter injection.

Let us assume that a tracer $b$ (e.g., FB) was injected in $\mathrm{B}$ and a tracer $y$ (e.g., DY) in C (Fig. 18).

If the neurons projecting to both $B$ and $C$ conform in their connectivity to the same topographical rules as the neurons that project to either $\mathrm{B}$ or $\mathrm{C}$, and if the failure to label is random, the probability that a neuron projecting to $\mathrm{B}$ and $\mathrm{C}$ will be labeled with both $\mathrm{b}$ and $\mathrm{y}$ cquals the product of the probabilities that it will be labeled by either $b$ or $y$ independently. Therefore,

$$
y b / y b_{\max }=\left(y / y_{\max }\right)\left(b / b_{\max }\right)
$$

where $y, b$, and $y b$ are densities of neurons labeled with the yellow, the blue and both tracers at a point sampled; $y_{\max }, b_{\max }$, and $y b_{\max }$ are the highest densities found of neurons labeled by the two dyes alone or in combination.

As shown in Figure 18, when $y_{\max }$ and $b_{\max }$ do not coincide in space, the real maximal density of neurons projecting via axon collaterals from $A$ to both $B$ and $C$ is higher than that actually found anywhere in the region where the populations of $y$ - and $b$-labeled neurons overlap:

$$
y b_{\max }=y b\left(y_{\max } / y\right)\left(b_{\max } / b\right)
$$

One can now calculate which proportion of $A$ neurons projecting to $B$ also project to $\mathrm{C}$,

$$
y b_{\max } / b_{\max }=(y b / b)\left(y_{\max } / y\right)
$$

and similarly, which proportion of A neurons projecting to $\mathrm{C}$ also project to $\mathrm{B}$,

$$
y b_{\max } / y_{\max }=(y b / y)\left(b_{\max } / b\right)
$$

Practically, when only one of the two ratios is wanted, sampling near the $b_{\max }$ or the $y_{\max }$ is convenient since it minimizes the amount of sampling. For example, as shown in Figure 18 , where $y_{\max }=y$,

$$
y b_{\max } / \mathrm{b}_{\max }=y b / b
$$

Similarly, where $b_{\max }=b$,

$$
y b_{\max } / y_{\max }=y b / y
$$

These considerations apply for tracers injected in the same or in different structures, simultaneously or not.

\section{Three-dye experiments}

The triple-labeling experiments described in this article dealt with the following situations: (1) neurons in A (area 17) were found to project to $C$ (ipsilateral area 18) after losing an axon to $B$ (contralateral areas 17 and 18). (2) Before the elimination of the A-to-B projection, some A ncurons send bifurcating axons to both $B$ and $C$. Are the sets of neurons in cases 1 and 2 identical? To answer this question, $b$ and $r$ (RL) were respectively injected in $\mathrm{B}$ and $\mathrm{C}$ before the axon elimination (at time $\mathrm{T} 0$ ) and $\mathrm{y}$ was injected in $\mathrm{C}$ after axon elimination (at time T1), as close as possible to the site of the $r$ injection.

In an ideal situation, with identical location and labeling efficiency of the $y$ and $r$ injections, if the sets of neurons 1 and 2 are identical, $y$ and $r$ will label identically. Therefore,

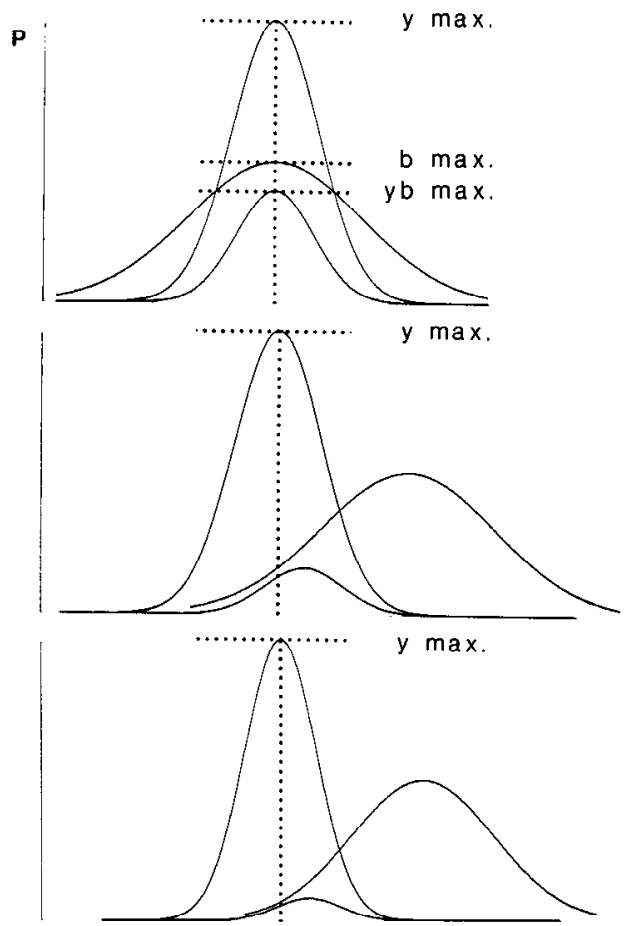

$\mathrm{mm}$

Figure 18. Distributions of neurons in structure A labeled either by the retrograde tracers y (highest Gaussian), b (middle Gaussian), or by both (lowest Gaussian). The profiles simulate distributions obtained by tracer injections in two structures (B and $C$ ) assumed to receive topographical projections from structure A. From top to bottom the two tracer injections are progressively shifted out of topographical correspondence. The curve of yb-labeled neurons was calculated from the equation $1 / y b=(1 / y)(1 / b)$, where $y, b$, and $y b$ are the densities of labeling $(P)$ with each tracer. The maximal $y, b$, and $y b$ labeling densities are also indicated. Note that the real $y b_{\max }$ is found only in the case of perfect topographical correspondence of the $y$ and $b$ injections. Direct estimates of the $y b_{\max } / b_{\max }$ ratios can, however, be obtained by counting labeled neurons as near as possible to the region of the $y_{\max }$ (vertical line). See also text.

$$
y b_{\max } / b_{\max }=b r_{\max } / b_{\max }=y b r_{\max } / b_{\max }
$$

In a real situation, there will usually be some mismatch between the $y$ and $r$ injections, but a substantial fraction of the neurons in $A$ that have sent an axon to $\mathrm{C}$ at the time of the $\mathrm{r}$ injection and still have it at the time of the $y$ injection will be double-labeled with both $r$ and $y$.

These neurons can be used to weigh the role of mismatches between the $y$ and $r$ injections, since the mismatch should affect the $r$ labelings of $y$ and $y b$ neurons equally. On this assumption,

$$
y b r / y b=y r / y
$$

It must be noticed that $y r / y$ overestimates the relabeling efficiency, if many neurons have bifurcating axons to both sites, of $y$ and $r$ injection.

If instead,

$$
y b r / y b<y r / y
$$

the following events may have occurred:

1. differential uptake of $r$ tracer by yb and y neurons (more $\mathrm{yb}$ neurons take $\mathrm{r}$ than $\mathrm{y}$ neurons)

2. increase in the number of neurons projecting from $A$ to $C$ between $\mathrm{T} 0$ and $\mathrm{T} 1$ (neurons that take up y but neither $\mathrm{r}$ nor b).

If

$$
y b r / y b>y r / y
$$

the following events may have occurred: 
1. differential uptake of $r$ tracer by yb and y neurons (less yb neurons take $r$ than y neurons)

2. some neurons grew an axon to $\mathrm{C}$ only after eliminating their axon to $B$ and were therefore not labeled by the $r$ injection on $\mathrm{T} 0$.

It must be noticed that a perverse combination of factors could lead to equality (8) without sets 1 and 2 being identical.

\section{References}

Adams, C. E., G. A. Mihailoff, and D. J. Woodward (1983) A transient component of the developing corticospinal tract arises in visual cortex. Neurosci. Lett. 36: 243-248.

Bentivoglio, M., H. G. J. M. Kuypers, C. E. Catsman-Berrevoets, and O. Dann (1979) Fluorescent retrograde neuronal labeling in rat by means of substances binding specifically to adenine-thymine rich DNA. Neurosci. Lett. 12: 235-240.

Bentivoglio, M., H. G. J. M. Kuypers, C. E. Catsman-Berrevoets, H. Loewe, and O. Dann (1980) Two new fluorescent retrograde neuronal tracers which are transported over long distances. Neurosci. Lett. 18: 25-30.

Berman, N. E., and B. R. Payne (1983) Alterations in connections of the corpus callosum following convergent and divergent strabismus. Brain Res. 274: 201-212.

Bunt, S. M., R. D. Lund, and P. W. Land (1983) Prenatal development of the optic projection in albino and hooded rats. Dev. Brain Res. 61: $149-168$.

Cajal, S. R. (1911) Transformación, por efecto traumático, de las células piramidales del cerebro en corpúsculos nerviosos de axon corto. Bol. Soc. Espan. Biol. 1: 127-129.

Clarke, S., and G. M. Innocenti (in press) Organization of immature intrahemispheric connections. J. Comp. Neurol.

Connors, B. W., L. S. Benardo, and D. A. Prince (1983) Coupling between neurons of the developing rat neocortex. J. Neurosci. 3: 773782.

Distel, H., and H. Holländer (1980) Autoradiographic tracing of developing subcortical projections of the occipital region in fetal rabbits. J. Comp. Neurol. 192: 505-518.

Elberger, A. J., E. L. Smith, III, and J. M. White (1983) Spatial dissociation of visual inputs alters the origin of the corpus callosum. Neurosci. Lett. 35: 19-24

Gilbert, C. D., and J. P. Kelly (1975) The projections of cells in different layers of the cat's visual cortex. J. Comp. Neurol. 163: 81106.

Gilbert, C. D., and T. N. Wiesel (1983) Clustered intrinsic connections in cat visual cortex. J. Neurosci. 3: 1116-1133.

Glaser, E. M., and H. Van der Loos (1965) A semi-automatic computer-microscope for the analysis of neuronal morphology. IEEE Trans. Biomed. Eng. BME-12: 22-31.

Innocenti, G. M. (1979) Two types of brain plasticity? Prog. Brain Res. 51: 479-487.

Innocenti, G. M. (1980) The primary visual pathway through the corpus callosum: Morphological and functional aspects in the cat Arch. Ital. Biol. 118: 124-188.

Innocenti, G. M. (1981) Growth and reshaping of axons in the establishment of visual callosal connections. Science 212: 824-827.

Innocenti, G. M., and R. Caminiti (1980) Postnatal shaping of callosal connections from sensory areas. Exp. Brain Res. 38: 381-394.

Innocenti, G. M., and S. Clarke (1983) Multiple sets of visual cortical neurons projecting transitorily through the corpus callosum. Neurosci. Lett. 41: 27-32.

Innocenti, G. M., and S. Clarke (1984a) Bilateral transitory projection to visual arcas from auditory cortex in kittens. Dev. Brain Res. 14: $143-148$.

Innocenti, G. M., and S. Clarke (1984b) The organization of immature callosal connections. J. Comp. Neurol. 230: 287-309.

Innocenti, G. M., and D. O. Frost (1979) Effects of visual experience on the maturation of the efferent system to the corpus eallosum. Nature 280: 231-234.

Innocenti, G. M., and D. O. Frost (1980) The postnatal development of visual callosal connections in the absence of visual experience or of the eyes. Exp. Brain Res. 39: 365-375.

Innocenti, G. M., L. Fiore, and R. Caminiti (1977) Exuberant projection into the corpus callosum from the visual cortex of newborn cats. Neurosci. Lett. 4: 237-242.

Innocenti, G. M., D. O. Frost, and J. Illes (1985) Maturation of visual callosal connections in visually deprived kittens: A challenging critical period. J. Neurosci. 5: 255-267.

Insausti, R., C. Blakemore, and W. M. Cowan (1984) Ganglion cell death during development of ipsilateral retino-collicular projection in golden hamster. Nature 308: 362-365.

Ivy, G. O., and H. P. Killackey (1982) Ontogenetic changes in the projections of ncocortical ncurons. J. Ncurosci. 2: 735-743.

Ivy, G. O., H. J. Gould, III, and H. P. Killackey (1984) Variability in the distribution of callosal projection neurons in the adult rat parietal cortex. Brain Res. 306: 53-61.

Kalia, M., and D. Whitteridge (1973) The visual areas in the splenial visual sulcus of the cat. J. Physiol. (Lond.) 232: 275-283.

Katz, L. C., A. Burkhalter, and W. J. Dreyer (1984) Fluorescent latex microspheres as a retrograde neuronal marker for in vivo and in vitro studies of visual cortex. Nature 310: 498-500.

Keizer, K., H. G. J. M. Kuypers, A. M. Huisman, and O. Dann (1983) Diamidino yellow dihydrochloride (DY-2HCl); a new fluorescent retrograde neuronal tracer, which migrates only very slowly out of the cell. Exp. Brain Res. 51: 179-191.

Keller, G., and G. M. Innocenti (1981) Callosal connections of suprasylvian visual areas in the cat. Neuroscience 6: 703-712.

Koppel, H., and G. M. Innocenti (1983) Is there a genuine exuberancy of callosal projections in development? A quantitative electron microscopic study in the cat. Neurosci. Lett. 41: 33-40.

Lund, J. S., G. H. Henry, C. L. Macqueen, and A. R. Harvey (1979) Anatomical organization of the primary visual cortex (area 17) of the cat. A comparison with area 17 of the Macaque monkey. J. Comp. Neurol. 184: 599-618.

Luskin, M. B., and C. J. Shatz (1985) Studies of the earliest generated cells in the cat's visual cortex: Cogeneration of subplate and marginal zones. J. Neurosci. 5: 1062-1075.

Montero, V. M. (1981) Topography of the cortico-cortical connections from the striate cortex in the cat. Brain Behav. Evol. 18: 194-218.

O'Leary, D. D. M., and W. M. Cowan (1982) Further studies on the development of the isthmo-optic nucleus with special reference to the occurrence and fate of ectopic and ipsilaterally projecting neurons. J. Comp. Neurol. 212: 399-416.

O'Leary, D. D. M., and B. B. Stanfield (1985) Occipital cortical neurons with transient pyramidal tract axons extend and maintain collaterals to subcortical but not intracortical targets. Brain Res. 336: 326-333.

O'Leary, D. D. M., B. B. Stanfield, and W. M. Cowan (1981) Evidence that the early postnatal restriction of the cells of origin of the callosal projection is due to the elimination of axonal collaterals rather than to the death of neurons. Dev. Brain Res. 1: 607-617.

O'Ieary, J. I. (1941) Structure of the area striata of the cat. J. Comp. Neurol. 75: 131-161.

Otsuka, R., and R. Hassler (1962) Uber Aufbau und Gliederung der corticalen Sehsphäre bei der Katze. Arch. Psychiatr. Zeitschr. Neurol. 203: 212-234.

Palmer, L. A., A. C. Rosenquist, and R. J. Tusa (1978) The retinotopic organization of lateral suprasylvian visual areas in the cat. J. Comp. Neurol. 177: 237-256.

Panneton, W. M., and D. L. Tolbert (1984) The collateral origin of a transient cerebrocerebellar pathway in kittens. A study using fluorescent double-labeling techniques. Dev. Brain Res. 14: 247-254.

Schneider, G. E. (1973) Early lesions of superior colliculus: Factors affecting the formation of abnormal retinal projections. Brain Behav. Evol. 8: 73-109.

Schwartz, M. I., and P. S. Goldman-Rakic (1982) Single cortical neurones have axon collaterals to ipsilateral and contralateral cortex in fetal and adult primates. Nature 299: 154-155.

Segraves, M. A., and G. M. Innocenti (1985) A comparison of the distribution of ipsilaterally and contralaterally projecting corticocortical neurons in cat visual cortex using two fluorescent tracers. J. Neurosci. 5: 2107-2118.

Sholl, D. A. (1955) The organization of the visual cortex in the cat. J. Anat. (Lond.) 89: 34-46.

Simpson, I., B. Rose, and W. R. Loewenstein (1977) Size limit of molecules permeating the junctional membrane channels. Science 195: 294-296.

Stanfield, B. B., D. D. M. O'Leary, and C. Fricks (1982) Selective collateral elimination in early postnatal development restricts cortical distribution of rat pyramidal tract neurones. Nature 298: 371-373.

Symonds, L. L., and A. C. Rosenquist (1984a) Corticocortical connections among visual areas in the cat. J. Comp. Neurol. 229: 1-38. 
Symonds, L. L., and A. C. Rosenquist (1984b) Laminar origins of visual corticocortical connections in the cat. J. Comp. Neurol. 229: $39-47$.

Tolbert, D. L., and W. M. Panneton (1983) Transient cerebrocerebellar projections in kittens: Postnatal development and topography. I. Comp. Neurol. 221: 216-228.

Tolbert, D. L., R. C. Dunn, Jr., and G. A. Vogler (1984) The postnatal development of corticotrigeminal projections in the cat. J. Comp. Neurol. 228: 478-490.

Tsumoto, T., K. Suda, and H. Sato (1983) Postnatal development of corticotectal neurons in the kitten striate cortex: A quantitative study with the horseradish peroxidase technique. J. Comp. Neurol. 219: 88-99.

Tusa, R. J., and L. A. Palmer (1980) Retinotopic organization of areas 20 and 21 in the cat. J. Comp. Neurol. 193: 147-164.

Tusa, R. J., L. A. Palmer, and A. C. Rosenquist (1978) The retinotopic organization of area 17 (striate cortex) in the cat. J. Comp. Neurol. 177: 213-236.

Tusa, R. J., A. C. Rosenquist, and L. A. Palmer (1979) Retinotopic organization of areas 18 and 19 in the cat. J. Comp. Neurol. 185: $657-678$. 